Identification and Analysis of Critical Gaps in Nuclear Fuel Cycle Codes Required by the SINEMA Program

Nuclear Energy Research Initiative Project

DOE FC07-07ID14839

Final Report

Adrian Miron, Ph.D. (Principal Investigator)

Joshua Valentine

University of Cincinnati

Nuclear and Radiological Engineering Program

Collaborators: John M. Christenson, Ph.D.

Majd Hawwari

Santosh Bhatt

University of Cincinnati, Nuclear and

Radiological Engineering Program

Mary Lou Dunzik-Gougar, Ph.D.

Jianwei Chen, Ph.D.

Michael Lineberry, Ph.D.

Daniel Phares

Nathan Zohner

Idaho State University, Nuclear Engineering Department 


\section{Identification and Analysis of Critical Gaps in Nuclear Fuel Cycle Codes Required by the SINEMA Program}

\section{Nuclear Energy Research Initiative Project \\ DOE FC07-07ID14839}

\section{Final Report}

Acknowledgements__ ii

Abstract__ 1

1. Introduction 2

2. Research Objectives and Workscope _ 5

3. Participants and Organizational Roles___ 6

4. Research Strategy 8

4.1 Nuclear Fuel Cycle Code Review Criteria __ 9

4.2 Questionnaire Development___ 10

4.3 Internet Resources on NFC Codes__ 10

4.4 Literature Research _ 12

4.5 National Laboratories, Universities, Nuclear Industry and Other Organizations12

4.6 Project Webpage _ 14

5. Results_ 16

5.1 Nuclear Fuel Cycle Code Database __ 18

5.2 Potential Gaps in Nuclear Fuel Cycle Codes __ 21

5.3 Nuclear Fuel Cycle Code Linkage __ 23

6. Conclusions — 26

7. Future Work__ 30

References _ 31

Attachment 1 - NFC Code Questionnaire and Web Form __ 32

Attachment 2 - Project Webpage__ 35

Attachment 3 - List of NFC Codes in Database__ 40

Attachment 4-Examples of Queries __ 45 


\section{Acknowledgements}

First, we would like to thank the U.S. DOE's Office of Nuclear Energy, Nuclear Energy Research Initiative Program, for it s financial support for this research project. Also, we express our appreciation for the assistance offered throughout this project by

Bernadette Kirk - Oak Ridge National Laboratory (ORNL),

Dr. G. Ivan Maldonado - University of TenesseeT/ORNL,

Dr. Dmitry Paramonov - Westinghouse,

Chris Juchau - former Idaho State University graduate student. 


\section{Abstract}

The current state of the art in nuclear fuel cycle (NFC) modeling is an eclectic mixture of codes with various levels of applicability, flexibility, and availability. In support of the advanced fuel cycle systems analyses, especially those by the Advanced Fuel Cycle Initiative (AFCI), University of Cincinnati (UC) in collaboration with Idaho State University (ISU) carried out a detailed review of the existing codes describing various aspects of the nuclear fuel cycle and identified the research and development (R\&D) needs required for a comprehensive model of the global nuclear energy infrastructure and the associated nuclear fuel cycles. Relevant information obtained on the NFC codes was compiled into a relational database that allows easy access to various codes' properties. Additionally, the research analyzed the gaps in the NFC computer codes with respect to their potential integration into programs that perform comprehensive NFC analysis.

The NFC code review included domestic and international, top-level, nuclear enterprise model codes, down to micro-scale model codes dealing with all aspects of the nuclear fuel cycle. The codes were assessed through a systematic approach that focused at least on the following features: input/output (I/O) data; functional and design requirements; method of solution; strengths and weaknesses; computer language and platform and capability to link with other codes.

The information obtained in the NFC code review was organized in a flexible and easy to update relational database. This database represents a first comprehensive reference on available nuclear fuel cycle codes that makes possible the identification of further needs on various modeling aspects of the entire nuclear cycle. It is expected that DOE and/or its sub-contractors will appropriately populate the database, as new models and codes become available. Students and scientists alike will be able to study the entire nuclear fuel cycle through the codes that model it and identify the appropriate models to be used in their research.

This research provides deliverables that are of complementary value to larger and more global efforts of this type, such as the Simulation Institute for Nuclear Enterprise Modeling and Analyses (SINEMA) program, formerly managed at Idaho National Laboratory, since it identifies potential codes to be linked for a comprehensive modeling of the entire nuclear fuel cycle and new $R \& D$ required to accomplish this goal. In addition, the database developed here, which represents a modern organization of information on existing NFC codes, may be used to create/refine the Application Program Interface for the top level codes, as envisioned by SINEMA. Other applications for the use of the database developed here are also detailed in this report. 


\section{Introduction}

The current state of the art in nuclear fuel cycle (NFC) modeling is an eclectic mixture of codes with various levels of applicability, flexibility, and availability. In support of the advanced fuel cycle systems analyses, especially those by the Advanced Fuel Cycle Initiative (AFCI), University of Cincinnati (UC) in collaboration with Idaho State University (ISU) carried out a detailed review of the existing codes describing various aspects of the nuclear fuel cycle and identified the research and development (R\&D) needs required for a comprehensive model of the global nuclear energy infrastructure and the associated nuclear fuel cycles. The research focused on both domestic and internationally developed codes and relevant information was compiled into a relational database that allows easy access to various codes' properties. Additionally, the research analyzed the gaps in the NFC computer codes with respect to their potential integration into programs that perform comprehensive NFC analysis.

At the time this proposal was developed, one of such broad-scope NFC programs, the Simulation Institute for Nuclear Enterprise Modeling and Analyses (SINEMA), was managed at the Idaho National Laboratory (INL). Some of the SINEMA's objectives were to develop a simulation network that can model the global nuclear energy infrastructure and associated fuel cycles and to provide information of use to decision/policy makers on best/optimal ways to further the development of advanced NFC.

While recognizing that nuclear energy systems and associated enterprise are very complex, involving not only a detailed understanding of technical, economic, political, social and environmental issues, but also balancing at the same time, national interests against international concerns, SINEMA scientists recognized the need for high-fidelity, integrated simulation of complex nuclear systems. Admitting that advanced computing and simulation have made remarkable progress in the last decades, SINEMA researchers promoted that it was the time to use basic science insights to further the prospects for nuclear power with the goal of decreasing design margins, reducing experimental programs in support of the design process and shortening the developmental design cycle while simulating new phenomena that have not been conceived before because of lack of key experimental data.

To develop its simulation network, SINEMA proposed to use a multi-tier, multi-scale, multi-temporal and multi-purpose simulation and modeling strategy based on a pyramidal architecture, as illustrated in Figure 1. At the top of the pyramid, there is a systems model of the global nuclear fuel cycle that is targeted primarily for decision and policy makers [1]. As part of the SINEMA project, a code named Global Evaluation of Nuclear Infrastructure Utilization Scenarios (GENIUS) is being developed to fill this role [2]. 


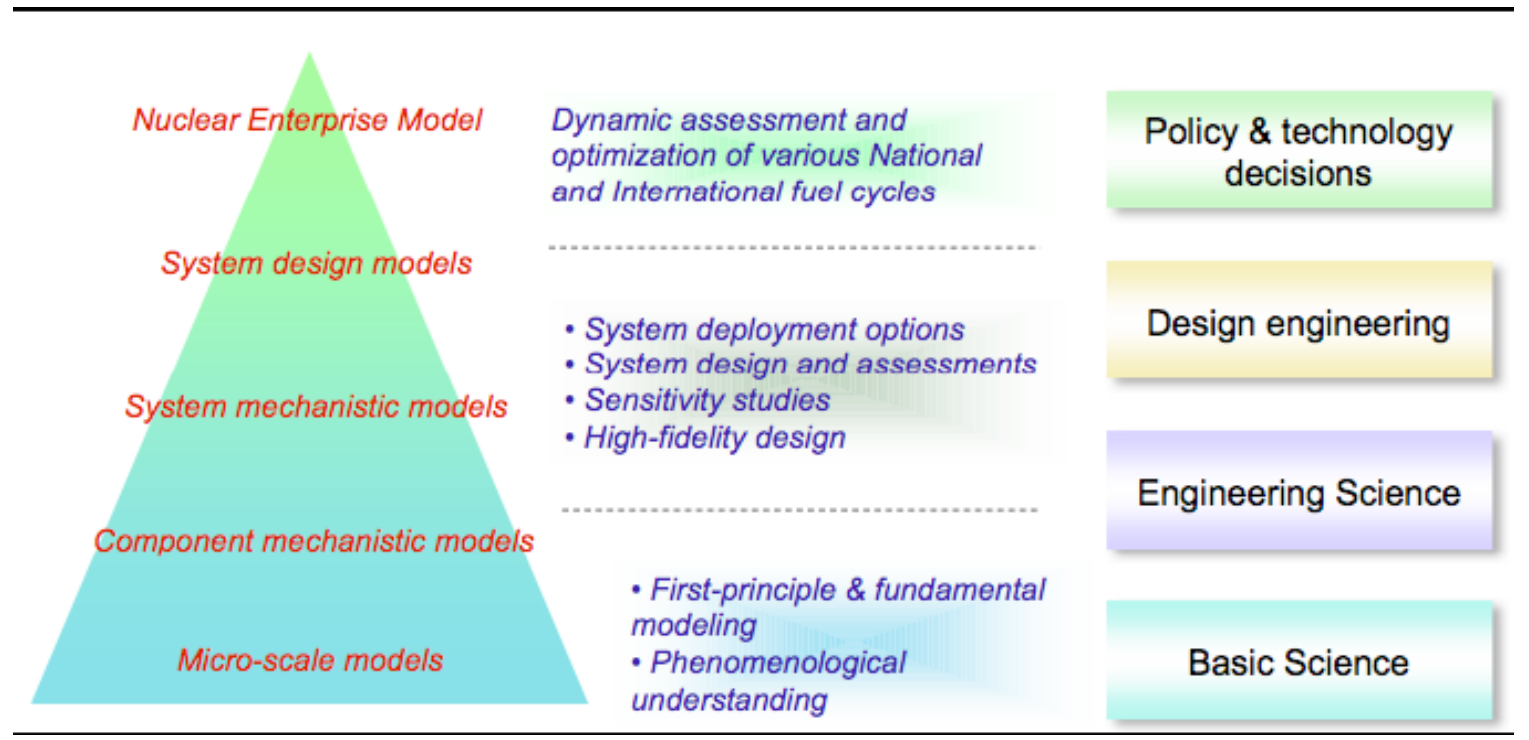

Figure 1 - SINEMA interactive pyramid architecture

One of the most important concepts in the SINEMA architecture is the idea of interconnection between various level codes. For instance, a code at a given level of granularity will provide input to the next, less detailed code(s) above and will, in turn, receive the output of a more rigorous code at lower pyramid levels. Links among codes will be hard or soft, depending on the specific application. The NFC top level code should connect, directly or indirectly, to any other code in the pyramid in order to obtain the desired level of detail for the NFC analysis.

Continuing downwards from the top of the pyramid, at the system design level, the deployment options of various systems should be quantified (e.g. different types of reactors, separation facilities, fuel fabrication facilities, etc.). The characteristics of the deployed systems are defined at a coarse, semi-empirical level. These analyses performed with a coarse-mesh may define the needs for the detailed models that constitute the next level of modeling, system mechanistic models [1].

At the third level, various mechanistic models that are needed to analyze the system characteristics (thermal-hydraulics, neutronics, structural, mechanics, etc.) will function in an orchestrated manner to develop a virtual design of the given system (reactor, separations plant, etc.). Complementary to these efforts, design improvements and the design data-needs at engineering scale can be considered at this level [1].

The fidelity of the system mechanistic models depends on the detailed mechanistic model of the critical components. The critical components can be defined through sensitivity studies in the system mechanistic models. Once developed, the component mechanistic models can be used to define component level design optimizations and the supporting testing needs [1].

Finally, micro-scale modeling based on first principles may be used to support the component models. These models can range from atomistic scale to continuum scale. 
Typical examples would be modeling fuel and material performance under irradiation, elemental behavior in storage facilities, etc [1].

In an initial effort, the SINEMA scientists evaluated existing nuclear fuel cycle systems models in order to determine what may be used in developing the top-level GENIUS code [3]. It soon became clear, as it was also tacitly acknowledged by the nuclear engineering community, that there are many codes that model various components of the nuclear fuel cycle. Also, as this research illustrated, some codes exist across several levels, having features of many detail levels.

This research builds on these preliminary review results, but went several steps further in performing a systematic and detailed review of nuclear fuel cycle (NFC) codes. The review covered both domestic and international nuclear engineering codes, from toplevel, nuclear enterprise models to system, components and micro-scale models, and focused on the code input/output (I/O) data. In addition, all the information obtained was organized into a database that allows for easy searches and retrieval of codes' properties. This new and modern organization allowed for identification of NFC R\&D needs as well as for an efficient use of the existing models/expertise by identifying codes that can be linked into the SINEMA's top model so that it will effectively accomplish its design specifications.

As detailed in Section 2, the above paragraph represents this research's objectives. Also, although this project was initially envisioned to entirely support SINEMA's research, it become very soon clear that this research has its own identity. First, the database developed here represents the first and only modern organization of information on existing NFC codes. It allows for various searches on various codes' properties, including codes' input and output parameters that were the focus of this research. If properly maintained and updated, it can be a valuable tool for researchers to study the entire nuclear fuel cycle through the codes that model it and identify the appropriate models to be used in their research. It can also be used to identify Application Programming Interfaces (API) for the entire or various parts of the nuclear fuel cycle. Other potential applications are discussed in Section 7.

Although the SINEMA program was stopped at the end of 2007, we believe that many characteristics that led to its occurrence are still valid today, and therefore, efforts of this type will continue in the future. If this happens, the database developed here may be a vital tool in modeling advanced nuclear fuel cycles. 


\section{Research Objectives and Workscope}

This research had three main objectives, as detailed below.

\section{Carry out a detailed review of the existing codes describing aspects of the nuclear fuel cycle.}

The review included both domestic and international codes and considered all level models, from top-level, nuclear enterprise models to system, components and microscale models. The review focused on the code input/output (I/O) data. This objective also included the design and organization of the information gathered on the NFC codes into a relational database as to allow for easy identification of possible combinations of models that cover the entire nuclear fuel cycle. This objective represented the bulk of the proposed research and lasted more than a year.

Only the last version of the code was included in the database. Also, many thermalhydraulic codes, excepting those widely used by the nuclear engineering community, were disregarded.

2. Identify the research and development $(R \& D)$ needs required to develop a comprehensive model of a global nuclear energy infrastructure and associated nuclear fuel cycles.

3. Identify and recommend codes to be linked within the SINEMA framework architecture.

The last two objectives were achieved by designing and running appropriate queries on the database developed in this project.

All the research objectives were successfully achieved. As indicated in this report, the last two objectives were directed to support the SINEMA program, but the results discussed below may be used in efforts of similar type.

Although not included in the original proposal, a web page was developed for this project as well. The website help researchers achieve the required consistency for the nuclear fuel cycle code review, post the achievements and the research results, and provide for a more professional, formal, secure, and fast communication with potential collaborators.

Last but not least, some results of this research were published in the Summer 09 Transaction of the American Nuclear Society Annual Meeting, while a journal paper is currently under development at University of Cincinnati. 


\section{Participants and Organizational Roles}

This project gave the opportunity for two professors and three graduate students in the Nuclear and Radiological Engineering at University of Cincinnati (UC) to participate on various aspects of this research. One professor was the Principal Investigator (PI) for this project while the other provided helpful support. Two of the UC students were Ph.D. Candidates, while for the third UC student, this work represented his MS project.

Three professors in the Nuclear Engineering Department at Idaho State University (ISU) and three ISU students (two graduate and one undergraduate) also participated, at various times, during this project. One of the ISU professors was also the co-PI for the SINEMA project.

Biweekly progress meetings were usually held between UC and ISU to monitor the progress and coordinate various tasks in this project.

The bulk of the research was performed at UC while ISU provided valuable support. The following tasks were mutually agreed upon at various times during the project:

For the first objective above:

\section{University of Cincinnati}

1.1 Developed questionnaires and template letters

1.2 Performed internet research on NFC codes

1.2.1 Appropriate US government organizations

1.2.2 All US national laboratories

1.2.3 Largest industry vendors and private companies

1.2.4 Domestic and foreign universities

1.2.5 Other national and international organizations

1.2.6 Foreign Organizations

1.3 Gathered and maintain information on NFC codes

1.4 Designed NFC code database

1.5 Input pertinent information into the database

1.6 Developed and sent quarterly progress reports to the DOE 


\section{Idaho State University}

1.1 Performed literature research on NFC codes

1.2 Provided information for all codes developed by Idaho National Laboratory

1.3 Provided quarterly progress reports to UC

For the second and third objective above:

\section{University of Cincinnati}

2.1 and 3.1Analyzed database and run pertinent queries

In addition, in 2009, a graduate student presented some partial results of this research in front of his peers at UC and at the annual American Nuclear Society Conference in Atlanta, GA, as part of his MS degree requirements, while the PI presented partial results at the 2009 NERI Project review meeting in August 2009. The PI also was also invited and presented information on this research during Nuclear Engineering seminars at several universities in U.S. 


\section{Research Strategy}

Per the appropriations stated in the awarded budget, accounts were set up at both UC and ISU. After a series of interviews conducted at UC, two students were selected to perform the research. One student was a Ph.D. candidate in the UC Nuclear and Radiological Engineering (NRE) Program and had experience in several nuclear fuel cycles codes. The other student was recently admitted in the NRE graduate program, completed introductory courses on nuclear fuel cycles and light water reactors, and recently obtained a BS in mechanical engineering with a minor in computer science. It was established that this work would be part of his MS degree requirements. The UC PI and the students met several times to discuss the scope and research steps for the project. Afterwards, weekly progress meetings were also established at UC to report on the research status and continued throughout the project.

Several teleconferences took place among UC and ISU in order to establish a workscope, as detailed in Section 3, for the ISU students. After the ISU workscope was agreed upon, the teleconferences were usually held every other week.

In accordance with the project tasks detailed in Section 3, the first stage of the research included a systematic and detailed review of the nuclear fuel cycle codes. This stage included the development of appropriate questionnaires and typical letters to be submitted to code developers and their organizations. The questionnaire included the required information on the NFC codes that were expected to also represent the main fields for the relational database.

Correspondence with all organizations identified in Task 1.2 above was maintained at UC and ISU at all times. Although very time consuming, this helped in obtaining information that was not present on the internet or published in the literature on several important NFC codes.

Although not specified in the proposal workscope, a website for this project was designed and developed at UC [4]. The web page has the capability to fill in the NFC code review questionnaire on line and includes other information about this project, such as: project description; a mini survey; contact information for the team currently working on the project; progress reports; and some other useful links. The mini survey was used to gather information about the nuclear fuel cycle codes the world-wide researchers have ever used and the problem these codes were used for, as a check that all pertinent NFC codes were considered.

The website helped us achieve the required consistency for the NFC code review and provide for a more professional, formal, secure and faster communication means with potential collaborators. Finally, links to the database and various pre-programmed queries on its nuclear fuel cycle codes were embedded in the web page. 
Two main avenues were established for performing the NFC code review: 1) Internet research; and 2) literature research. Both avenues had a domestic as well as a foreign component. As per the agreement between the two institutions, UC was in charge for the first avenue, while ISU covered the second.

Approximately a year after the NFC code review, the database design was developed in parallel with Tasks 1.2 and 1.3 at UC and 1.1. and 1.2 at ISU. It was considered at that time that all the required fields in the database were identified from the information already gathered. The database suffered several modifications, but when the design was finally completed, data on a few codes was entered and a few queries were run to test if the design was appropriate. Upon successful completion of the tests, NFC code data was entered in the database in parallel with the NFC code review.

Once all gathered information on NFC codes was entered in the database, several queries were designed to accomplish the last two project tasks: what are the R\&D needs for modeling the entire nuclear fuel cycle and what are the codes that can be linked together to model it.

\subsection{Nuclear Fuel Cycle Code Review Criteria}

A set of criteria was developed to use as basis in evaluating each NFC code. The information was grouped into 17 categories. The main focus of these 17 pieces of information about each code was the input and output parameters. It was expected that $\mathrm{I} / \mathrm{O}$ parameters would be paramount in determining the last two objectives for this research.

The 17 criteria that were decided upon were as follows:

Code Name:
Version:
Author(s):
Availability/Cost:
Contact Point:
Type of Problem Modeled:
Mining/Milling
Conversion
Enrichment
Fuel Fabrication
Reactor Analysis
Fuel Storage
Fuel Reprocessing
Waste Disposal
Method of Solution:
Important Features:
Restrictions/Limitations:


Computer Platform:

Coding Language:

Typical Run Times:

Auxiliary Programs Used:

Input Parameter Description

Output Parameter Description

Major Projects where code was used:

References:

These criteria are at the foundation of the questionnaire and database design, as detailed below.

\subsection{Questionnaire Development}

A questionnaire was developed to obtain the required information about each code that was of interest. The required information was grouped into the 17 categories presented in Section 4.1. These also represent fields in the relational database that was later developed. Out of the 17 pieces of information about each code, the main focus of this research was on the I/O parameters.

The questionnaire was initially developed as a Word document, allowing contributors to cut and paste information directly into it. Later, this Word document was converted into a PDF document. This PDF also allowed simple cut and paste of data but in a more structured presentation. In order to gather information in this manner, the PDF would need to be emailed to a potential contributor, the data would need to be filled into the document then emailed back to the research team. In attempting to streamline the data gathering process, eliminating this multi step process was of concern.

Ultimately, a web form was created to allow contributors to input data and simply click a submit button. The web form was of the same format and asked for the same 17 pieces of information as the forms and allowed for cut and paste input while easing the process of emailing a document back and forth. This greatly streamlined the data collection process.

The questionnaire and the web form are shown in Attachment 1.

\subsection{Internet Resources on NFC Codes}

Upon establishing the set of 17 criteria for each code, existing internet resources were identified and examined for pertinent NFC codes and related information. A thorough internet research effort was performed at UC. It began by examining three previously developed resources: the Radiation Safety Information Computational Center (RSICC) [5]; Energy, Science and Technology Software Center (ESTSC) [6], both maintained at Oak Ridge National Laboratory, and Nuclear Energy Agency (NEA) Data Bank [7]. 
These tools provided a sound starting point for the information sought. All three resources contain information about a number of codes and provide most of the information needed for this research. However, all of them lack code input and output parameter description or do not list them.

Upon examining the RSICC, ESTSC and NEA tools, each resource contained nearly 1,400 codes. Not all codes contained in each of the resources were pertinent to this research and needed to be systematically discussed and eventually eliminated. With ISU's help, contact was established with NEA in France and appropriate procedures to obtain information on NFC codes of interest in this resource were indentified and established through RSICC. In the U.S., RSICC supplies information on codes listed on their website once the registration, request, user software license, and export control agreement are cleared for export compliance by the Department of Energy (DOE). UC requested two such approvals, which DOE approved; UC also obtained user manuals for most of the codes of interest.

Thus, once the proper procedures were in place, the three internet tools were reviewed for information on codes in line with this research. It was found that most of the codes are common to all three internet resources; however, there were a few that are unique to each organization.

Further review of the RSICC database reduced the large amount of codes to a manageable list of interest. This list was then forwarded to RSICC and the missing data, namely input and output parameters were requested. The initial review produced a list of approximately 70 codes that were found to be of interest to this research. With the help of the RSICC personnel, the requested codes were reduced to eliminate obsolete codes and codes not related to the project scope. The list of codes of interest from the RSICC database was reduced to 26 codes. The list excluded codes that were modules for other top level codes or outdated codes that no longer work on modern hardware.

Information on any codes listed in the NEA and ESTSC internet resources that were not included in the RSICC resource were obtained upon request from RSICC. Finally, a detail analysis of the pertinent information was performed on the documentation (user manuals) provided from the RSICC at UC.

A fourth similar internet tool thoroughly examined was the International Atomic Energy Agency (IAEA) website. Examining the IAEA website resulted in one code of interest for this research. This was the NFCSS - Nuclear Fuel Cycle Simulation System top level nuclear fuel cycle code. Based on our workscope detailed Section 2 above, the research on the IAEA database produced no further codes of interest. Most of the information needed in this project to analyze this code was found directly on the IAEA website. There was no need to establish a contact avenue as the information was easily obtained.

Once the documentation was received through and from the RSICC, essential information about the code's input and output was extracted and analyzed. This data was ultimately filled in an internally developed database. Once the relational database was designed and 
functional, pertinent information on these codes was extracted from these documents and included in our NFC code database.

\subsection{Literature Research}

One area of research that can be fruitful is a literature search and such an investigation was taken on by ISU. The literature research started at ISU with the review of the American Nuclear Society transactions No. 97. In addition, standard databases have been used to carry out the literature review on NFC codes going back as far as 1989. A list of domestic and international nuclear cycle codes was compiled as a result of this research.

Few potential codes of interest were discovered and added to the running list due to literature research. Most of the code discovered through this research had previously been identified. Information on the few new codes that were discovered and not previously obtained through existing resources was obtained through direct contact with the codes' authors.

While literature review revealed only a few new NFC codes of interest for this research, it also showed that most of these focused on very specific applications and thus, are limited in scope. Combination of codes are usually used and reported in the literature as to broaden the scope of research. This part of the research was very important since it also showed the researchers' preferences for several codes or combination of codes for the NFC studies.

\subsection{National Laboratories, Nuclear Industry, Universities, and Other Organizations}

Along with the existing Internet tools, all DOE national laboratories web pages were examined. Several of the codes developed by these laboratories had previously been discovered through the internet tools, but a few had not.

All DOE national laboratories sites were reviewed by UC with the exception of Idaho National Laboratory, which was ISU's responsibility. Several codes of interest were identified for further review from all other DOE national laboratory sites. Establishing contact at each laboratory to obtain pertinent information about these codes was performed. More specifically, communications with Argonne National Laboratory and Los Alamos National Laboratory provided information required for the codes developed at those institutions that were not included in the RSICC resource.

Major vendors and power producing companies in the nuclear power industry were targeted for codes that had not been identified. Venturing into this arena, it was clearly understood that issues of intellectual property and proprietary information would surface. These potential sources were approached very carefully and cautiously to ensure the objective of the research was understood and to maximize potential of contribution. This is a good example of where the project web page was shown to be very useful. Naturally, 
when this phase of the project started, a large volume of questions were fielded. Avoiding composition of lengthy emails was alleviated by directing personnel to the informative and resourceful web page. This allowed potential contributors to familiarize themselves with the project and perhaps motivate them to contribute to a valid and useful research project.

The most willing and most fluid contributor was Studsvik. Initial contacts were smooth as Studsvik was willing to contribute without much resistance. Detailed information was provided by Studsvik via the questionnaire for two major industry codes, CASMO and SIMULATE. At first, limited information for the input and output parameters were given. A follow-up request for additional information was met by providing some documents from which $\mathrm{I} / \mathrm{O}$ parameters were extracted.

Westinghouse was also willing to contribute to our research. The communication process was very lengthy with Westinghouse. Initially they were apprehensive in releasing data on their software. Issues of intellectual property and competitor knowledge were of concern to the company. As noted, this was to be expected and retarded the contribution efforts. Ultimately, Westinghouse provided several pieces of information about four nuclear fuel cycle codes developed in house: ALPHA, ANC, PARAGON and PEARLS. This information was provided by filling out the questionnaire that had been developed. However, a complete list of input and output parameters was not provided for any of these codes. Partial information vaguely describing the input and output parameters was given for some codes while information on one code simply stated "More than 350 input parameters. Please refer to ALPHA manual" although the user manual had not been provided [9]. This can be attributed to their concerns stated above.

Attempts to seek contribution from General Electric (GE) were unsuccessful in this research. At the 2007 American Nuclear Society (ANS) fall conference, an initial contact at GE agreed to help with this research, and was perused as a valuable contact for GEdeveloped codes. A list of potential codes of interest was provided and this list was used as a basis for information requests. Unfortunately, our GE contact was denied rights to release "such detailed information" by the GE upper management in Wilmington. The GE management expressed that the requested list of codes' input and output parameter was "sensitive and competitive in nature" [10]. Again, such a position by vendors was expected to be encountered. This was especially disconcerting as the communication process with GE was lengthy and typically changed positions as the request moved up the management ladder. Nonetheless, GE did not contribute based on UC's efforts.

At the same ANS conference, an AREVA representative also agreed to help in this research. Again, this contact was vigorously pursued as a valuable contact for AREVAdeveloped codes. Although this lead seemed promising in the beginning, contact was eventually lost. Since the first contact did not produce any results, with the help of ISU, another AREVA representative was contacted in request for contribution. A list of codes used by AREVA in US and Europe was obtained, but, as with GE, requests for information pertaining to these codes were denied and unfortunately, AREVA "declined to participate in this research" [11]. 
The codes developed by both GE and AREVA were included in our codes of interest list and ultimately in the database with the limited information obtained on each code.

Several power producing companies were contacted to investigate which codes were used at those facilities. It was found from contacts at Duke Energy, American Electric Power, Florida Power and Light Company and FirstEnergy Nuclear Operating Company that the utilities usually "run vendor codes" for the plants' fuel management operations and do not develop their own codes [12]. Therefore, Studsvik, Westinghouse, AREVA, and GE were the potential sources for obtaining information on the industry in-house codes, as originally thought.

The internet research performed at UC included websites of domestic and international universities that have nuclear engineering programs and departments. A few NFC codes of interest were discovered while documentation on them was obtained without out any difficulty.

Multiple attempts were made to establish contact with the Department of Atomic Energy in India, Chinese Atomic Energy Authority in China, Ministry for Atomic Energy (Minatom) in Russia, Atomic Energy of Canada Limited (AECL) in Canada and other international organization through their respective websites. No results were obtained from these attempts.

Finally, research on Nuclear Energy Institute, Electric Power Research Institute, American Nuclear Society, U.S. Department of Energy, National Institute of Standards and Technology, U.S. Department of Transportation and U.S. Department of Defense websites produced no additional codes of interest for this research. However, investigation of the Nuclear Regulatory Commission website added a few codes to our list and NFC code database.

\subsection{Project Webpage}

Although not specified in the proposal work scope, a website for this project was designed and developed at UC [4]. This web page was created on the uc.edu domain to assure university affiliation. The web page is presently located at http://www.min.uc.edu/nuclear/current_research/sinema-research and shown in Attachment 2. The web site contains a thorough description of the research project and efforts as well as the accepted NERI abstract and award. While communicating with contributors, this page allowed us to properly and completely inform all participants, again while reaffirming the university association. As the research progressed, additional items were added to the web site. As more and more codes were identified a list was generated detailing the code name, author and where information on the code was obtained from. A list of research team members was also created. 
A mini survey was also added (see also Attachment 2). This was used to send out as a feeler to find potential contributors. This was sent out to all North American universities that had a nuclear engineering program hoping to discover all codes currently used in the academic arena. This mini survey asked only for Contact Information, Code Name, Project it was used on and any References. This allowed the research team to identify new codes that had not been found prior; is this happened, a request for additional information followed.

A page with useful links was also added that included several internet resources used and ultimately, after the data was entered in the database and the appropriate queries were developed, a php page with preprogrammed searches. This page represents an example of using the database over the internet and run queries that is of interest to the remote user. The page and examples of preprogrammed queries is shown in Attachment 2 and 4, respectively.

The project web page was useful as an information gathering and communication tool, as well as a way to inform contributors of the research focus and status. 


\section{Results}

The NFC code review resulted in 76 NFC codes of interest for this research, out of which complete or partial information was obtained for 52 NFC codes. This research also confirmed the existence of another 22 NFC codes, upon which no I/O information, which represented our focal point of interest, was obtained for various reasons detailed in Section 4. In addition, 2 codes are obsolete versions of other codes and are represented in the database only by name. All gathered information was included in our internally developed database.

As detailed in Section 2, no thermal hydraulics codes were included in our NFC code database, except several that are widely used by the nuclear engineering community.

Ten codes out of the 76 NFC codes discussed above are top-level, NFC codes, and complete or partial information about eight of them are included in our NFC database, while one of them is an obsolete (older version) code for which detailed information was not pursuit. There is only one multiple type code that deals with the front end of the cycle and 4 codes that deal with the back end of the cycle, out of which 2 are multiple type codes. The majority of codes in our database, 56, deal with in core fuel management, while essential data (I/O) on 14 of these are missing.

Finally, there are 8 codes designated in the "Other” category. These are codes that were either identified by name, but information was not fully gathered on them, or not completely in the scope of the research, but important industry codes. Four (4) are well represented in our NFC database. They are as follows: FRAPTRAN and TRACE - a transient and a thermo hydraulic code frequently coupled with other codes developed at PNNL and NRC respectively, SNAP - a framework for managing fuel cycle simulations developed at NRC, PENTRAN - a particle transport code that potentially has applications in fuel cycle modeling, and four codes identified but for which no information was obtained, two developed by GE and two by AREVA.

As expected, the majority of codes in our NFC code database were developed by U.S. National Laboratories: 27/3, out of which 2 were developed in cooperation with U.S. universities, and one in cooperation with an international organization. Henceforth, the number after the "/” represents codes that are included in our database but for which information on their I/O parameters was not obtained or the respective code is obsolete. Here, the three codes on which I/O parameters were not obtained are SCALE 6, TRITON, which is a SCALE 6 module, both developed at ORNL, and VEGAS developed at LANL. Unfortunately, obtaining information about the VEGAS was not completed. Several attempts were made to obtain this information but were unsuccessful. This code is not available from the RSICC or ESTSC resources. It was also discovered that some prior research had been performed on VEGAS, but obtaining information from those researchers was not successful. Information was requested from the RSICC for SCALE. At the time, SCALE 5.1 was the most current revision of the code. What was provided from the RSICC was simply a flier detailing improvements over SCALE 5 and 
not much detailed information. The RSICC was contacted again for complete information whereupon it was discovered that SCALE 6 had since been released. Attempts to obtain the documentation for SCALE 6 were unsuccessful due to untimely communication and project time constraints. Although this information should be available from the RSICC, ultimately, it was not included in the NFC database.

Nuclear industry is also a major contributor to our database: 26/19. However, for reasons detailed in Section 4, complete or partial I/O information was obtained only for a code developed by Advanced Computing Technologies, Inc, and as detailed in Section 4, for two codes developed by Studvik and for 4 codes developed by Westinghouse. The rest of the 19 industry codes, out of which one is obsolete, are represented only by name in our NFC code database. Nevertheless, based on information found in this research, all these are in-core fuel management codes, category, which is well represented in our NFC code research.

Universities were involved in the development of 10/0 codes represented in our research: two were foreign universities and the rest were domestic. Two U.S. universities developed codes of interest for this research in collaboration with National Laboratories, one in collaboration with several international organizations, and five universities developed their own codes. As mentioned previously, documentation of interest for these codes was readily obtained.

There are 16/2 codes in our NFC code database to which international or foreign organizations contributed. As specified above, one code was developed in cooperation with a U.S. National Laboratory, one in cooperation with a domestic university and 2 were developed by foreign universities. In addition, 7/0 codes were developed by foreign institutions, 3/1 were developed by international organizations and 2/1 were developed by foreign institutions in cooperation with international organizations. Out of the two codes that are poorly represented in our NFC code database, one is obsolete and for one we were unable to find $\mathrm{I} / \mathrm{O}$ information.

The list of codes in our NFC code database is shown in Attachment 3. The codes that are poorly represented in our database are marked with a “*” character.

Details about our NFC code database and the results of the queries that helped accomplish the other two objectives for this research are presented below. As mentioned above and per the worksope discussed in Section 2, all project objectives were accomplished with the following issues or concerns:

- Many thermal-hydraulic codes were disregarded (not within the project workscope)

- Obsolete code were disregarded; only limited information on some of them was included in the NFC code database (per the project workscope) 
- Many codes may be proprietary and/or have associated security issues (see discussion in Section 4.5). In addition, the PI and co-PIs of this research have knowledge that a reprocessing code is/was under development at INL (SESAME). However, no information on the I/O parameters for this code could be obtained during this research.

- SINEMA work was stopped (see discussion in Section 1)

- GENIUS work may be limited in scope. SINEMA's top level code, GENIUS, continued to be developed at University of Wisconsin. However, its design requirements, as established by the SINEMA researchers, may be limited due to different missions and/or insufficient resources of any of the top universities. In our opinion, such an endeavor should be carried out by a consortium formed by several universities and a few national labs, as originally envisioned by SINEMA researchers.

- Some codes may have been missed

\subsection{Nuclear Fuel Cycle Code Database}

As the data collection process progressed, an efficient, manageable data storage mechanism was sought, per the steps identified in Sections 3 and 4. This was examined and considered early in the project, but not developed until the latter stages after sufficient data had been collected. A relational database was chosen as the storage mechanism for the information gathered on the NFC codes of interest. The database design was also discussed with, and evaluated by, a UC professor who specializes in this field, and some important suggestions were made.

Initially, the development of the database was planned in Microsoft Access. The database expert suggested a development in MySQL, a Relational Database management System (RDMS). This suggestion was made due to the ease of implementing a MySQL database in a web environment. Using MySQL tends to be a more fluid process than other database systems in such an environment. MySQL is known as "the world's most popular open source database” and it is a very established database software [13].

The database was designed in a fashion that included a main data table, sub-data tables and linking tables for those sub-tables allowing one-to-many and many-to-many relationships. The main data table included items unique to each code that would not benefit from a one-to-many or many-to-many design. These items included data such as Code Name, Authors, Cost and Availability, Version number, Contact Information, etc.

The sub-data tables contain the information not included in the main data table that follow a many-to-many or one-to-many relationship. These data tables include the Computer Platform and Architecture, Coding Language, Method of Solution, Problem Type Solved, Subprograms the code uses, and finally I/O parameter data. Designing the database to accommodate such relationships was essential and eased the data entry 
process. For example, a fixed list of "Problem Type Solved" was generated and each code was associated with a/many problem type(s). A code could be just a reactor analysis code, or it could do multiple problem types. Also, multiple codes could be of a specific problem type. The database design compensates for such situations. This was especially helpful in dealing with the I/O parameters as it detailed parameter description and unit. Several different types of parameters can use the same units. Again, the database accounted for these types of situations and made data entry and organization very smooth.

Ultimately, the database designed in MS Access was populated with a few codes to ensure the design was solid and properly working. Next, using MS Access's simple point-and-click interface, several queries were designed to test the database and determine if the desired output is obtained. Again, this was performed to ensure proper functionality of the database to iron out potential design flaws before mass data input was performed. This was achieved providing further confirmation the design is sound and prepared for use. This is essential as altering a databases design after being populated can often cause very undesirable results.

After reaffirming a solid design and proper performance of the database in MS Access, the database was developed in MySQL, a RDMS that uses the Structured Query Language (SQL) as the name implies. Performing the database development in MySQL was thought to also ease the process in creating a final deliverable. This will, in turn, help other researchers use this tool more efficiently and remotely. Customized queries can be built into a PHP webpage, either hosted on a web server or in a standalone package that can run from a local workstation, as shown in the last section of Attachment 2.

The database tables and their relationships developed are shown in Figure 2. The database was designed around the questionnaire that was developed to include all 17 criteria gathered about each code, as specified in Section 4.1, with a main focus on input and output parameters. After development in MySQL was completed, the database was again populated with a small amount of data and several queries were tested. With the database design and structure working properly after several reviews and reworks, main code data population began.

With the input/output ( $\mathrm{I} / \mathrm{O})$ parameters being the main focus of this research, developing the parameters and naming conventions for data entry consumed the largest amount of time. This was performed to ensure duplicate entries for different codes would be avoided. One of the strengths of the database design is the account for many-to-many and one-to-many relationships. This allows for codes with many I/O parameters, which all have, and similar I/O parameters shared by many codes to be easily input into the database. Once the I/O naming conventions were established and with a number of code data entered, further additions came more fluidly. 
Relationships for NFCCodes_v3

Tuesday, September 22, 2009

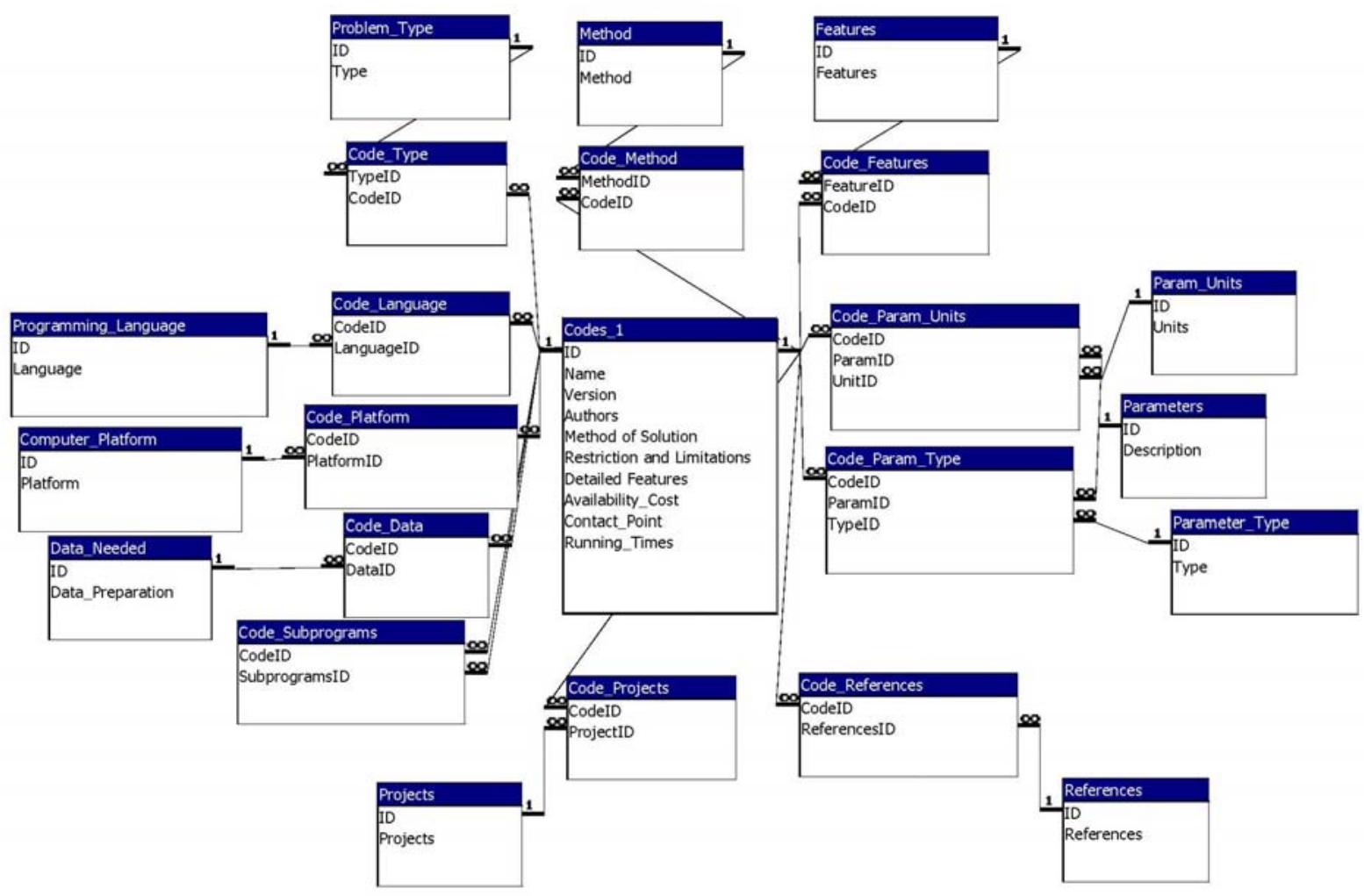

Figure 2 - NFC code Database Design and Relationships 
As seen in Figure 2, at the top and at the left of the main data table, there are sub-tables that include general information about the code that follow a many-to-many or one-tomany relationship (Problem Type, Method, Features, Programming Language, Computer Platform, Data and Subprograms needed to run a certain code). This information is readily available in the three internet resources discussed in Section 4.3 (RSICC, ESTSC and NEA Data Bank). However, the main focus of this research, the I/O parameters, is missing in these resources.

Besides the fact that our relational NFC code database includes above information, it also includes information about I/O parameters. This information was usually extracted from the code's user manuals or other pertinent documents sent by RSICC or the code's authors. This addition makes our NFC code database a unique and powerful application.

In addition, the sub-tables underneath the main data table (Project and References) may also represent a very useful and powerful tool in the future. These tables may hold references (in the form of papers, reports, articles, etc) or projects about certain NFC codes or combination or codes a potential developer of this database would input in the future. Currently, only references on user manuals or the other documents referred above are included in the database.

\subsection{Potential Gaps in Nuclear Fuel Cycle Codes}

Once the database was fully populated with data from all the nuclear fuel cycle codes of interest, various queries were designed in order to accomplish the two other main objectives for this project, i.e.: Identify R\&D needs and gaps in nuclear fuel cycle computer codes; and Identify best code packages to be linked within the SINEMA framework.

To approach the first objective an overview look of the data describing the 76 codes that were input into the database was examined. Table 1 shows the number of codes based on Problem Type. Of the codes included, one can see the vast majority of the codes available to this research were of the Reactor Analysis type.

Table 1: Overview of NFC codes by Problem Type

\begin{tabular}{|l|c|}
\hline Problem Type: & Number of Codes: \\
\hline Mining/Milling & 0 \\
\hline Conversion & 0 \\
\hline Enrichment & 1 \\
\hline Fuel Fabrication & 0 \\
\hline Reactor Analysis & 56 \\
\hline Spent Fuel Storage & 4 \\
\hline Fuel Reprocessing & 0 \\
\hline Waste Disposal & 0 \\
\hline Top level/Complete Fuel Cycle & 10 \\
\hline Other/Unknown & 8 \\
\hline
\end{tabular}


One code was discovered that will perform Enrichment calculations, the FSCNE code. Although this code is categorized as an enrichment code, it is also used for the Reactor Analysis and Spent Fuel Storage types. That is, it is a multi problem type code. Of the other three Spent Fuel Storage type codes, the $\mathrm{A}^{3} \mathrm{MCNP}$ code is also a Reactor Analysis code. That leaves two codes that are explicitly categorized as Spent Fuel Storage code types: SCANS 1A and REFREP.

The codes categorized as Other/Unknown include the thermal hydraulic code TRACE/RELAP. This code was included as it is the defacto NRC code and is typically coupled with many codes during reactor analysis. The other codes listed in that category are codes that have been identified but incomplete information was obtained on them and/or we were unable to properly identify them by problem type.

Table 2 displays a list of codes that were determined to model the complete fuel cycle. There were 10 codes in total identified, including the VISTA code that has been replaced by NFCSS at the IAEA, and thus is categorized as obsolete for this research. These codes are of great importance as they have attempted to model the entire fuel cycle previously and any short comings or advantages can be taken from these codes to generate the most complete model possible.

The remaining categories lack significant modeling codes within the scope of this research. Taking note of Table 1 , five categories of code problem types were not represented by any of the codes obtained aside from the complete cycle codes. Codes modeling current or future reactor designing using a Thorium fuel cycle were not found. None of the codes obtained in this research modeled breeder/fast reactors as well.

Table 2: List of Top level/Complete Fuel Cycle codes

\begin{tabular}{|l|l|}
\hline Code Name & Developer/Authors \\
\hline $\begin{array}{l}\text { CAFCA: Code for Advanced Fuel } \\
\text { Cycles Assessment }\end{array}$ & MIT \\
\hline COSI & $\begin{array}{l}\text { Developed by the Nuclear Energy Direction at CEA and the } \\
\text { French Atomic Energy Commission }\end{array}$ \\
\hline $\begin{array}{l}\text { DANESS - Dynamic Analysis of } \\
\text { Nuclear Energy System Strategies }\end{array}$ & $\begin{array}{l}\text { Argonne National Laboratory } \\
\text { Nuclear Engineering Division }\end{array}$ \\
\hline $\begin{array}{l}\text { NFCSim - Nuclear Fuel Cycle } \\
\text { Simulation }\end{array}$ & Los Alamos National Laboratory \\
\hline $\begin{array}{l}\text { NFCSS - Nuclear Fuel Cycle } \\
\text { Simulation System }\end{array}$ & International Atomic Energy Agency (IAEA) \\
\hline $\begin{array}{l}\text { SMAFS: Steady-State Analysis } \\
\text { Model for Advanced Fuel Cycle } \\
\text { Schemes. }\end{array}$ & $\begin{array}{l}\text { Nuclear Development Division } \\
\text { OECD/NEA }\end{array}$ \\
\hline VEGAS & Los Alamos National Laboratory \\
\hline $\begin{array}{l}\text { VSOP94: Very Superior Old } \\
\text { Programs }\end{array}$ & Institut fuer Sicherheitsforschung ind Reaktortechni \\
\hline VISION & Argonne National Laboratory and Idaho National Laboratory \\
\hline
\end{tabular}




\subsection{Nuclear Fuel Cycle Code Linkage}

This research showed that linking codes from one category to another was not possible, due to the fact that not enough codes exist in each category to attempt to link them. As Table 1 above shows, the Mining/Milling and Conversion categories contain zero codes, therefore no codes can be linked together. The enrichment category contains one code, but the adjoining categories, Conversion and Fuel Fabrication, contain zero codes.

Therefore, no codes can be linked. Because Fuel Fabrication contains zero codes, none can be linked to the Reactor Analysis category.

There are however 4 codes in the Spent Fuel Storage, but as stated above, the FSCNE and $\mathrm{A}^{3} \mathrm{MCNP}$ codes are multi category codes and can be linked into further projects.

Because only two other codes exist in the Spent Fuel category, SCANS 1A and REFREP, both may be considered. The Fuel Processing and Waste Storage categories contain zero codes, therefore none can be recommended for this project.

This leaves the Reactor Analysis codes. There are 56 codes identified in this category. Of those, several are recommended as a result of this research. Firstly, the MCNPMonteburns-ORIGEN coupling to perform burnup calculations is recommended, as found in the literature. Also, the industry codes that were contributed may also be considered. This includes ALPHA, ANC, NEXUS, Pearls, PARAGON, and POLCA by Westinghouse. Also, the two codes contributed from Studsvik, CASMO and Simulate.

In addition, the PEBBED code is recommended as it is the only code discovered in this research that deals with pebble bed reactors. The TRACE/RELAP code from the NRC is also recommended as it is a prominent thermal-hydraulic code. Also, based on the literature research results, well known codes as REBUS, MCNP and SCALE may also qualify.

Table 2 displays a list of codes that were determined to model the complete fuel cycle. There were 10 codes in total identified, with one of those being the VISTA code that has been replaced by NFCSS at the IAEA. These codes are of great importance as they have attempted to model the whole fuel cycle previously and any short comings or advantages can be taken from these codes to generate the most complete model possible. If all the remaining top-level (CAFCA, COSI, DANESS, NFCSim, NRCSS, SMAFS, VEGAS, VSO94 and VISION) codes were to be linked together, one may think that all the disadvantages would disappear. However, this may not be as simple as that. Coupling such complex codes may be very time consuming and may not result in the expected results. Error propagation between codes and uncertainty analysis would become a nightmare.

One solution is to start fresh, as the SINEMA researchers initially envisioned for the GENIUS code. Based on the experience and study of all these codes, a general design requirements documents can be developed. Some design objectives should include but not be limited to: 
1 Developing a very flexible framework for NFC analysis, including clearly delimitated components, modules and visual interfaces. This can be achieved through studying the I/O parameters of the NFC codes in our database, while the framework should be designed to accommodate all the other design objectives listed below.

2 A fully-modular approach with capability to use diverse systems, modules and technologies.

3 In a first step, developing of simple, dynamic models for each of the components and modules identified in various advanced NFC. The documentation gathered in this research may speed up these endeavors. As noted above, the framework should easily accommodate modifications/additions of modules so that the analysis becomes more complex with subsequent model updates.

4 In a first step, establishing simple relationships between modules and components. The framework should easily accommodate modifications/additions of such relationships so that the analysis becomes more complex with subsequent model updates.

5 Allowing for cost-benefit analysis, tracking of nuclear facilities and their characteristics, and accounting for expenditures and investments.

6 Allowing for discrete material tracking as a function of time and location, with preservation of material history and optimization of blending schemes, at least for

6.1 Raw materials (natural resources), processed materials, and nuclear materials transportation flow

6.2 Material storage

6.3 Products and by-products (Electricity, Hydrogen, Nuclear Waste, etc.)

7 Establishing/Developing a methodology for uncertainty analysis, with propagation of scientific uncertainty, modeling bias and technology confidence throughout the system. Accuracy should be sacrificed for speed (for now). Latin Hypercube Sampling or appropriate modifications of this method may be a candidate since it allows for variation of many parameters and statistical distributions while being relatively fast.

8 Establishing/Developing a methodology to perform system-, component- and module-level, multi-objective optimization in accordance with specific, user-defined scenarios.

9 Not giving up yet on the interplay between coarse and user-specified level of detail for the NFC analysis, establishing ways to link other codes into this framework, without sacrificing uncertainty analysis, optimization and uncertainty propagation tools. This may represent the biggest challenge to such a project but the benefits would be worthwhile. 
10 Saving the results of runs in specially designed relational databases that are dynamically created as the case/scenario run is defined.

Creating such an analysis framework allows for interplay between the real- and virtualworld NFC models. Thus, such a model may also become very attractive for safeguard applications, where the user can compare the real values with the modeled ones, while the model should allow for setting regulatory controls.

These are only some ideas for the long road ahead. Obviously, due to the limited time and workscope of this research, none of these were attempted. 


\section{Conclusions}

University of Cincinnati (UC) in collaboration with Idaho State University (ISU) carried out this research in support of the advanced fuel cycle systems analyses, especially those by the Advanced Fuel Cycle Initiative. This research provides deliverables that are of complementary value to larger and more global efforts of this type, such as the Simulation Institute for Nuclear Enterprise Modeling and Analyses (SINEMA) program, formerly managed at Idaho National Laboratory. In addition, by developing a useful nuclear engineering tool for identifying codes to be used in various projects, and establishing some other programmatic objectives important to the Nuclear Engineering Research Initiative (NERI) programs, as detailed at the end of this section, this research also ascertained its own identity.

The project successfully accomplished all its three main objectives initially identified.

First, a detailed review of the existing codes describing various aspects of the nuclear fuel cycle (NFC) was carried out. The review covered both domestic and international nuclear engineering codes, from top-level, nuclear enterprise models down to system, components and micro-scale models. The codes were assessed through a systematic approach that focused on their input/output (I/O) parameters but covered other aspects such as: functional and design requirements; method of solution; strengths and weaknesses; computer language and platform; capability to link with other codes, etc.

Two main avenues were established for achieving the NFC code review: 1) Internet research; 2) literature research. Intensive correspondence with codes' authors or contact points was also carried out.

The internet research included all U.S. national laboratories, appropriate domestic, international or foreign organizations and universities with nuclear engineering programs. Important internet resources on NFC codes and procedures for obtaining them, along with their documentations, were also identified. This avenue produced the most results in terms of identifying codes of interest for this research.

Most information on nuclear industry codes was obtained as a result of intensive correspondence with code's authors or contact points. This avenue also produced expected results for some codes developed by national laboratories or found in the literature.

While literature review revealed only a few new NFC codes of interest for this research, it also showed that most of these focused on very specific applications and thus, are limited in scope. Combination of codes are usually used and reported in the literature as to broaden the scope of research. This part of the research was very important since it also showed the researchers' preferences for several codes or combination of codes for NFC studies. 
Several NFC codes pertinent to this research were developed by universities and pertinent information on these was readily obtained. At the opposite spectrum with respect to the ease of obtaining relevant information, in particular codes' I/O parameters, was the nuclear industry. Venturing into this arena, it was clearly understood that issues of intellectual property and proprietary information would surface in this case. Only Studvik fully contributed, while Westinghouse provided partial information and AREVA provided only a list of codes they developed in house. GE did not participate in this research altogether.

Finally, the NFC code review resulted in 76 codes of interest for this research, out of which complete or partial information was obtained for 52 NFC codes. This research also confirmed the existence of other 22 NFC codes, upon which no I/O information was obtained for various reasons. In addition, 2 codes are obsolete versions of other codes and are represented in the database only by name. Per the project workscope, no thermal hydraulics codes are included, except several that are widely used by the nuclear engineering community.

The information obtained in the NFC code review was compiled in a flexible and easy to update relational database. This database represents the first and only modern organization of information on existing NFC codes. The database allows for various searches on various codes' properties, including codes' I/O parameters that were the focus of this research. Since this database currently represents the first comprehensive reference on available nuclear fuel cycle codes, we believe it is our greatest accomplishment in this project.

The organization of information into a relational database made possible the design of several queries used to identify $R \& D$ needs required for a comprehensive model of the global nuclear energy infrastructure and the associated nuclear fuel cycles, which represented the second objective for our research. The following statements are general conclusions on our findings:

- This research confirmed that most of the codes found here were initially developed 20 or 30 years ago, and just a few are suffering periodic updates. The tremendous progress in computing power should make it ripe for creating a framework to comprehensively model the NFC at a level of detail established by the potential user. This R\&D aligns perfectly with SINEMA’s vision.

- With the exception of the current top level NFC codes, very few codes are concerned with the front- or back- end of cycle. Most of the codes found in this research deal with in-core fuel management and reactor design. While the front-end of the NFC may potentially be easily modeled, a reprocessing code is paramount for the NFC studies of a closed cycle. At the same time, we have knowledge that a reprocessing code is/was under development at INL (SESAME). However, detailed information on this code may be hard to obtain due to proprietary and/or security concerns. 
- Very few codes may be used for fast reactor design or to accommodate other advanced NFCs, such as a thorium cycle. Again, this becomes paramount for studying advanced and closed nuclear fuel cycles.

The third objective of this research was to identify and recommend codes to be linked within the SINEMA framework architecture. Table 1 shows that linking codes from one NFC category to another was not possible because not enough codes exist in each category to attempt to link them. In addition, Section 5.3 discusses usual coupling between reactor codes found in the literature, existing top level NFC codes and some general design requirements that are not met in their entirety by any of the existing top level NFC codes.

This research also developed several questionnaires and template letters that were submitted to code developers and their organizations. One of the questionnaires included the required information on the NFC codes while the other was created to gather information about the nuclear fuel cycle codes the world-wide researchers have ever used and the problem these codes were used for, as a check that all pertinent NFC codes were considered.

Although not specified in the proposal workscope, a website for this project was designed and developed. It has the capability to fill in the questionnaires on line and includes other information about this project, such as: project description; contact information for the team currently working on the project; progress reports; and some other useful links. The website helped us achieve the required consistency for the NFC code review and provide for a more professional, formal, secure and faster communication means with potential collaborators. Finally, links to the database and various pre-programmed queries on its nuclear fuel cycle codes were embedded in the web page. Based on our experience here, a web page should be designed and developed for any project that lasts for more than two years.

In addition, partial results of this research were presented at the 2009 American Nuclear Society Conference in Atlanta, GA, at the 2009 NERI Project review meeting as well as in front of nuclear engineering students and faculty at several universities.

No commercialization potential was identified for this research. On the contrary, we believe that the database information and its queries should be publicly available to any researcher interested in the NFC codes.

Finally, we believe that at least three programmatic contributions to the NERI program objectives were achieved during this research:

- A better organization of information on NFC codes, including creating the foundation for potential data collection on NFC code references and associated projects; 
- Created the opportunity for 6 students (5 graduates and one undergraduate), as well as for 5 professors at two universities to study the nuclear fuel cycle through their respective models. One student made this work his MS project.

- Database developed in this project may be used to refine, validate and/or modify the Application Program Interface (API) for models of the entire or various parts of the nuclear fuel cycle. 


\section{Future Work}

Although all research objectives were successfully accomplished, some other potential applications and future work have also been identified. First and foremost, for the research results not to become obsolete, ways to maintain/update/grow the database and associated resources should be found. The results of the database searches are as good as its design and data included. While we believe that the database design is sound, we certainly agree that the information included in it can be improved, new data added, etc.

As discussed in this report, the database tables may hold references (in the form of papers, reports, articles, etc) or projects about any NFC codes or combination or codes. This data needs to be input into the database, but once this is accomplished, the database may represent a huge source of reference on any code in it, or any combinations of codes used in various project, etc.

As discussed in this report, the database developed in this project and the documentation gathered in this project may be used to refine, validate and/or modify the Application Program Interface (API) for models of the entire or various parts of the nuclear fuel cycle. Although the SINEMA program was stopped at the end of 2007, we believe that many characteristics that led to its occurrence are still valid today, and therefore, efforts of this type will continue in the future. If this happens, the database developed in this project may be a vital tool in helping to comprehensively model the entire fuel cycle at the desired level of detail.

Finally, a Journal paper on this research is under development at University of Cincinnati. We believe that this research has some unique, modern and useful characteristics and the results discussed here may interest a larger audience. 


\section{References}

[1] Pasamehmetoglu, K., Gougar, M.L.D, "SINEMA: Simulation Institute for Nuclear Energy Modeling and Analysis," a Laboratory Directed Research and Development project at the Idaho National Laboratory, Project ID AE115 (2004).

[2] Juchau, C., Gougar, M.L.D., Pasamehmetoglu, K., "Simulation Institute for Nuclear Energy Modeling and Analyses (SINEMA): Developing a GENIUS”, Trans. Am. Nuc., Vol. 94, June 2006.

[3] Juchau, C., Gougar, M.L.D., “A Review of Nuclear Fuel Cycle Systems Codes,” Idaho National Laboratory Technical Memorandum, April, 2006.

[4] Identification and Analysis of Critical Gaps in Nuclear Fuel Cycle Codes Required by the SINEMA Program, Project Webpage, http://www.min.uc.edu/nuclear/current_research/sinema-research, Last visited: 09/30/09.

[5] Radiation Safety Information Computational Center (RSICC), http://rsicc.ornl.gov/index.html, Last visited: 09/30/09.

[6] Energy, Science and Technology Software Center (ETSCC), http://www.osti.gov/estsc/index.jsp, Last visited 09/30/09.

[7] Nuclear Energy Agency Data Bank NEA Data Bank, http://www.nea.fr/html/databank/welcome.html, Last visited 09/30/09.

[8] International Atomic Energy Agency, Nucleus website, http://www.iaea.org/OurWork/ST/NE/NEFW/nfcms_infcis_VISTA.html, Last visited 09/30/09.

[9] Correspondence with Dr. Dmitri Paramonov at Westinghouse, 2008.

[10] Correspondence with Dr. Eric Loewen at GE, 2008.

[11] Correspondence with James Hulsman at AREVA, 2008.

[12] Personal communication with Robert Borland at FirstEnergy Nuclear Operating Company (FENOC), Tom Geer at Duke Energy and Consuelo Rodriguez, Florida Electric Power Company, 2008.

[13] "MySQL:: the world's most popular open source database”, http://www.mysql.com/, Last visited 09/30/09. 


\section{Attachment 1 - NFC Code Questionnaire and Web Form}

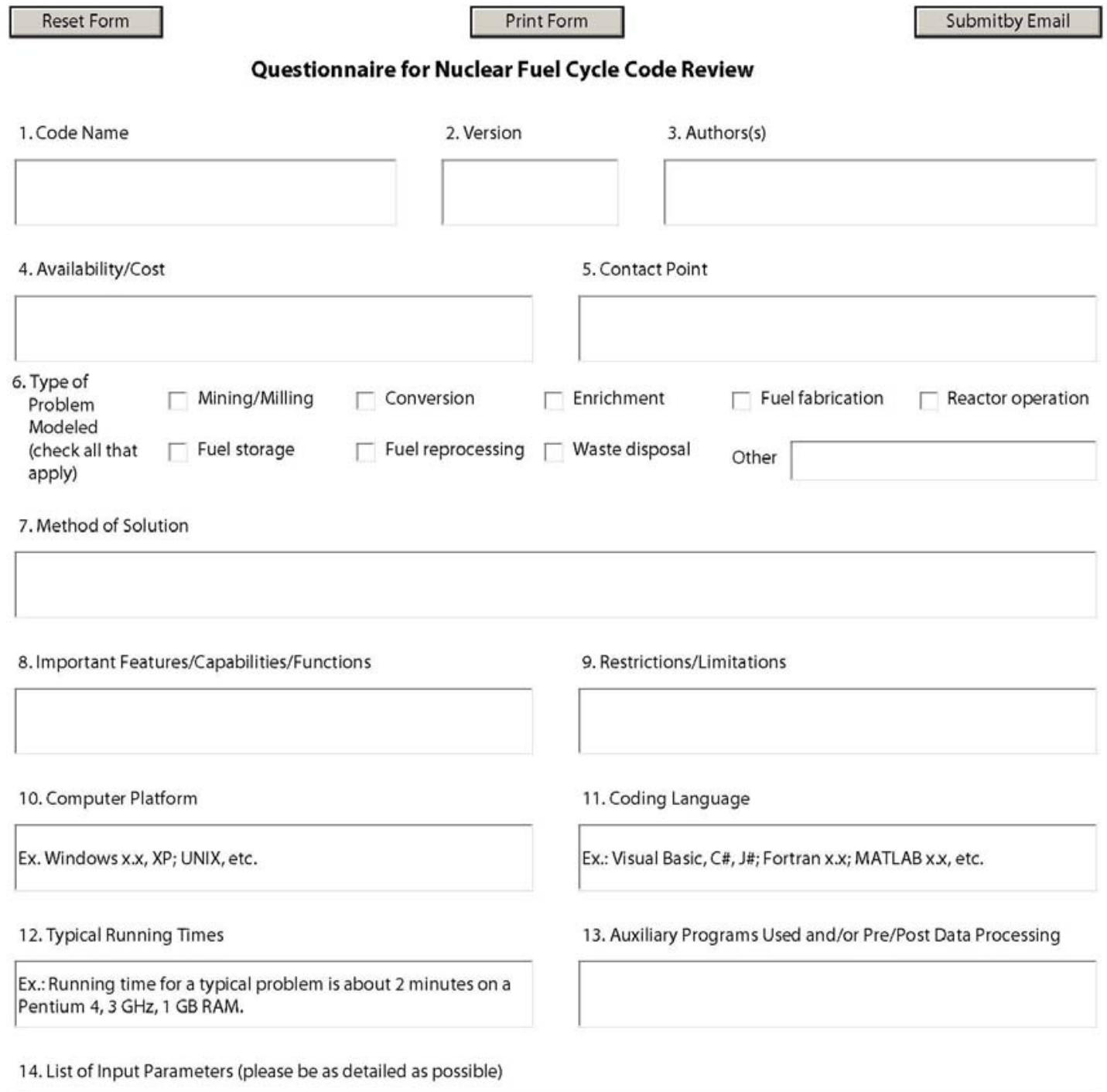

15. List of Calcualted Output (please be as detailed as possible)

16. Major Projects where Code Was Used (if known)

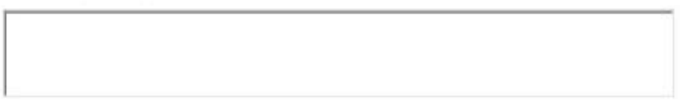

The NFC Code Questionnaire - PDF form

17. References 


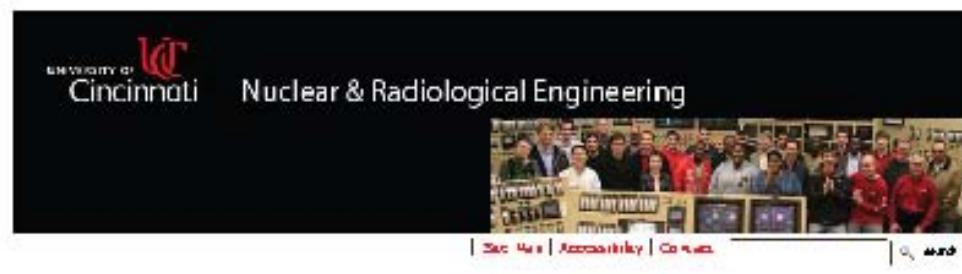

$m=$

maky

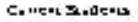

$4 \mathrm{mos}$

Fonet

ventoma.

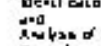

Cinlo

Ga
4.cks"
relckek

pelcek

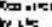

S14t is

पnd

4ek

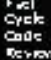

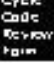

$\operatorname{sen} 2$

conos

gito
inesen

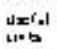

trescos

u,ane

fencion 4 .ete.

Yxiny

Pagiene

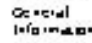

ca $x$ a

जenाय.

Cئ日.

-sta

(1)

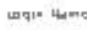

!nowrado

5

a

Nuclear Fuel Cycle Code

Review Form

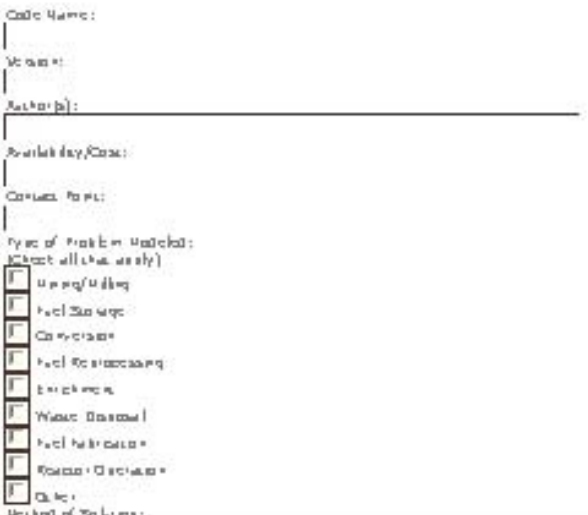

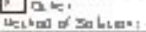

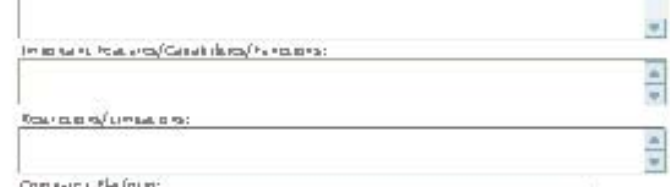

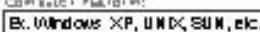

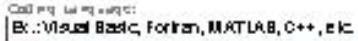

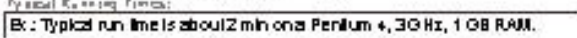

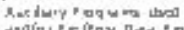

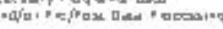

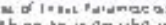

amait t]

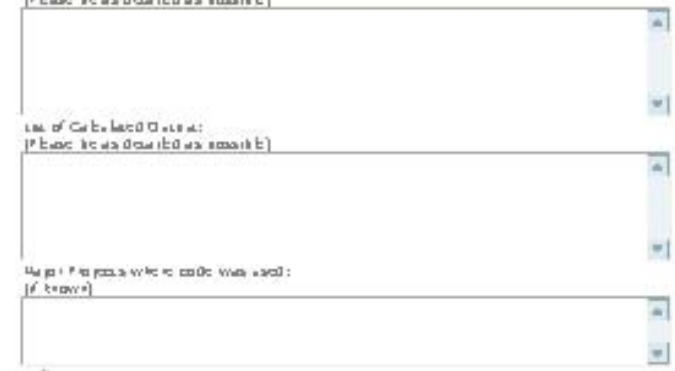




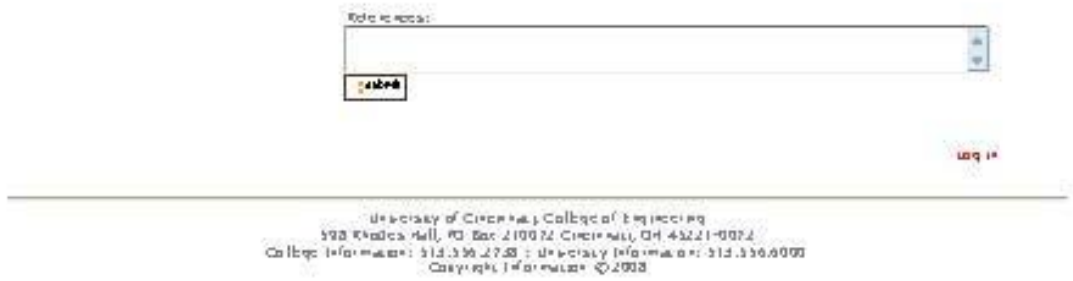

The NFC Questionnaire - Web Form

(http://www.min.uc.edu/nuclear/current_research/sinema-research/nuclear-fuel-cyclecode-review-form) 


\section{Attachment 2 - Project Webpage}

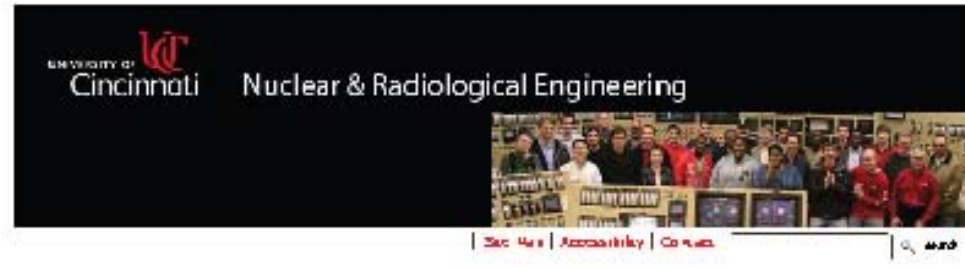

$\rightarrow \infty$

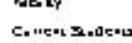

Howa

soses

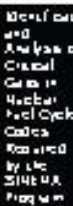

Identification and Analysis of Critical Gaps in Nuclear Fuel Cycle Codes Required by the SINEMA Program

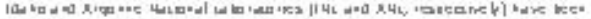

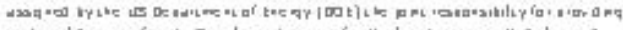

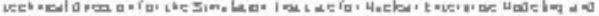

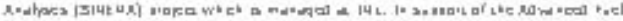

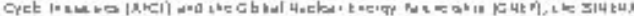

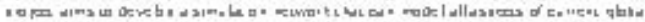

4 sas.

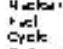

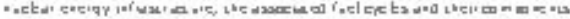

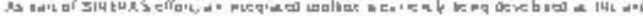

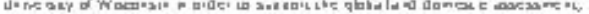

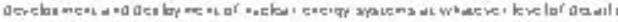

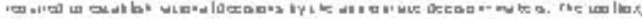

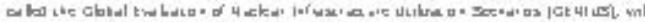

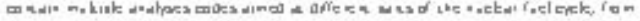

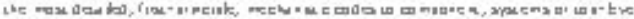

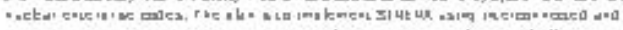

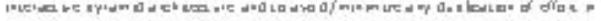

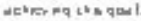

tresta

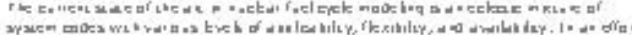

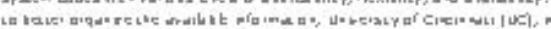

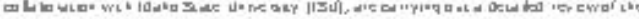

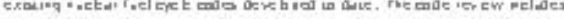

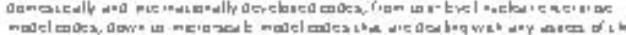

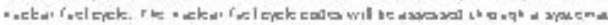

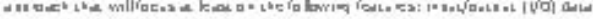
r.

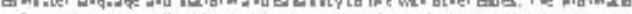

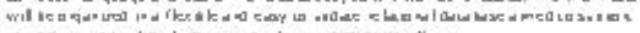

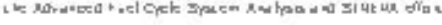

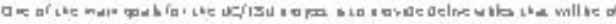

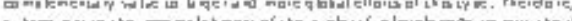

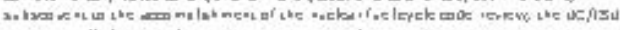

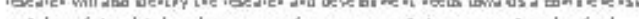

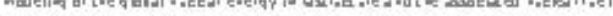

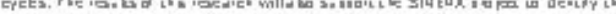

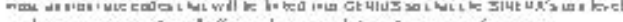

แथवा:

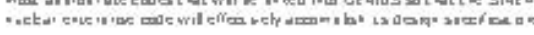

(4)

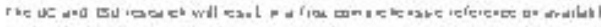

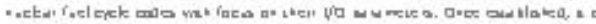

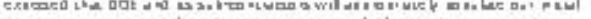

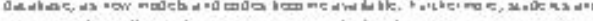

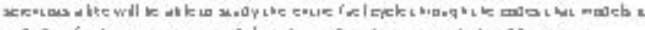

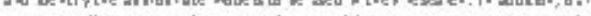

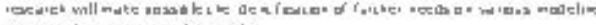

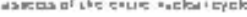

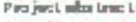

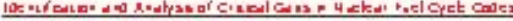

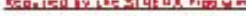

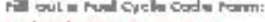

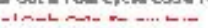




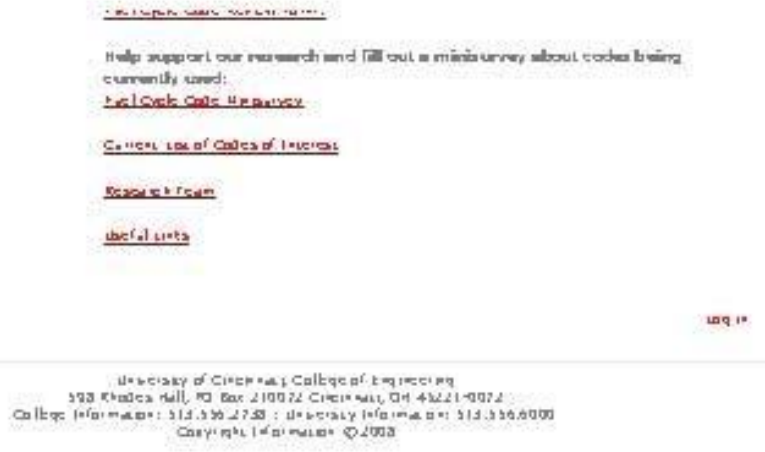

Main Project web page (http://www.min.uc.edu/nuclear/current_research/sinemaresearch) 


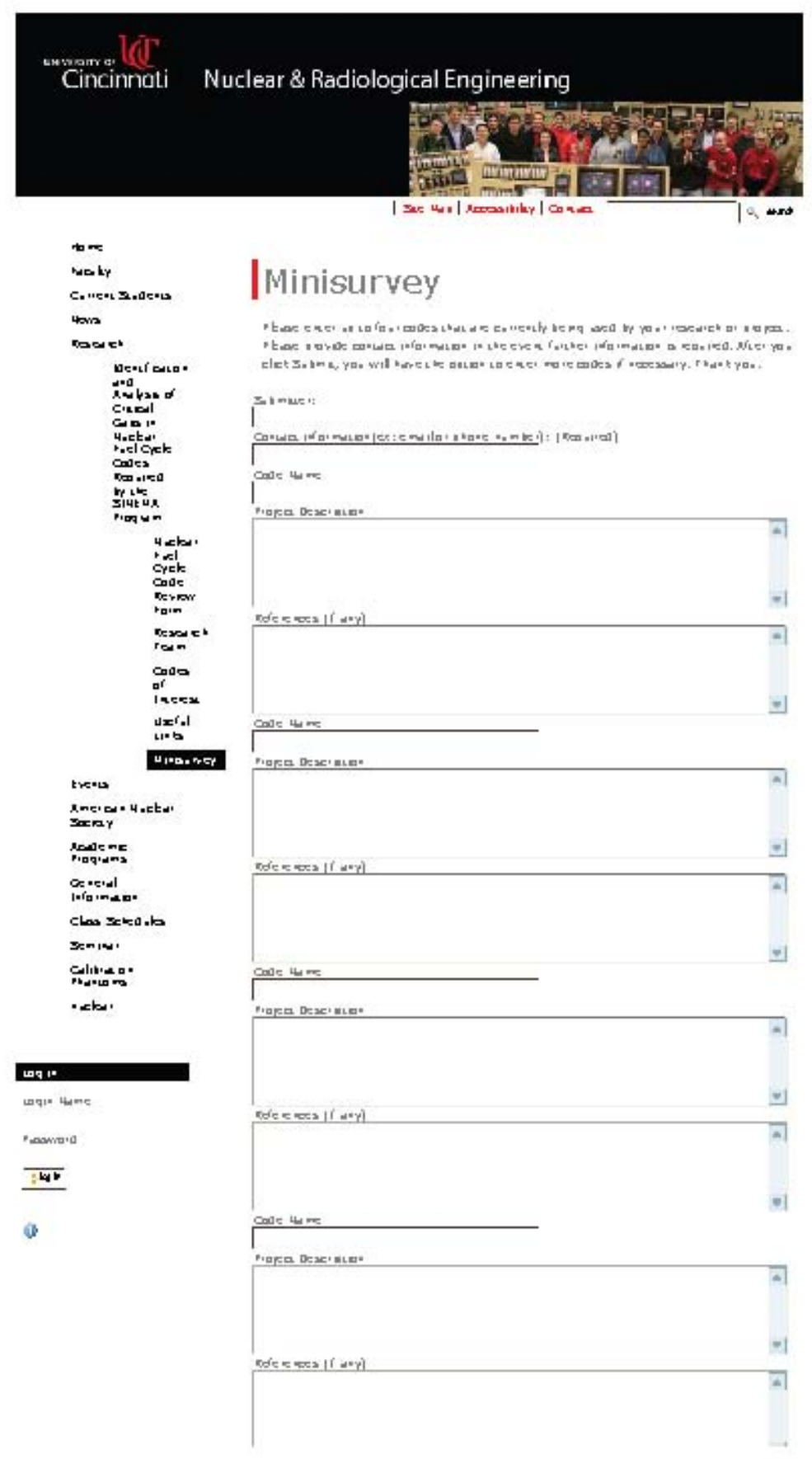




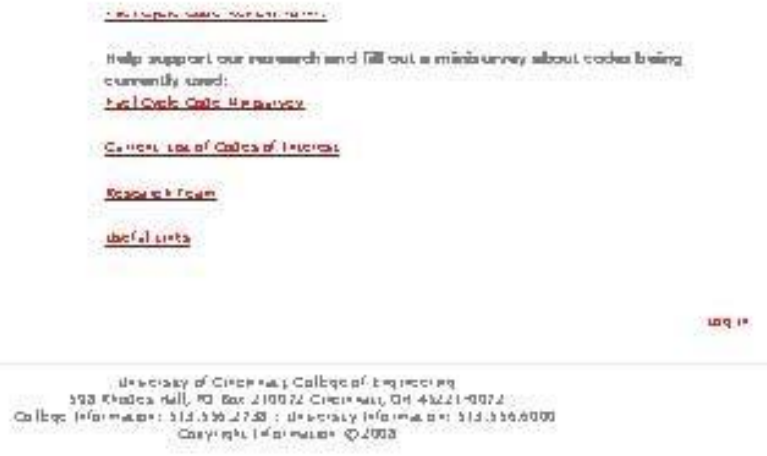

Minisurvey sent repeatedly to all Universities that have nuclear engineering programs in North America (http://www.min.uc.edu/nuclear/current_research/sinemaresearch/minisurvey) 


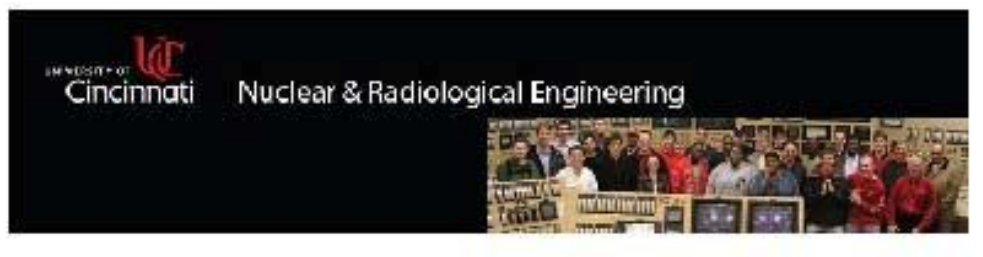

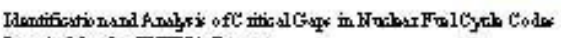

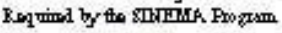

Complote Codo $L \dot{s}+\mathrm{A}_{2 x}$

Problem IYT \&

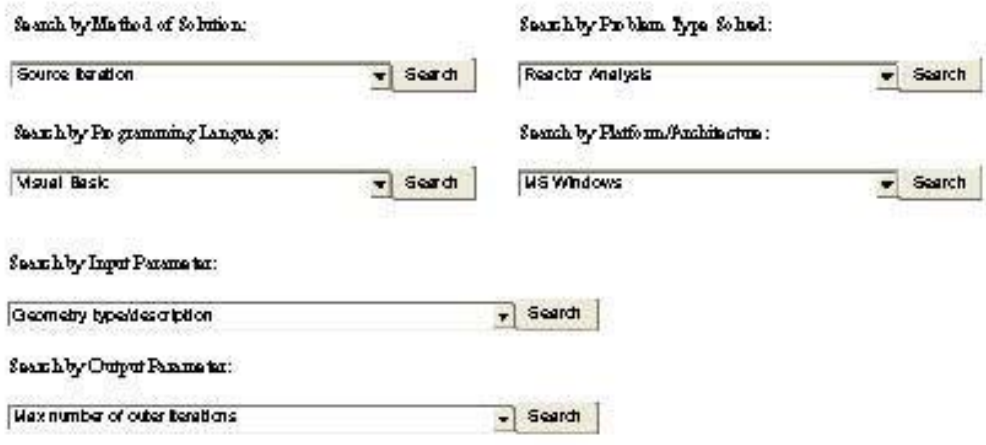

Queries on the NFC code database developed in this research that can be run by remote users (http://homepages.uc.edu/ valentja/main.php) 


\section{Attachment 3 - List of NFC Codes in Database}

* = Code discovered but I/O information was not obtained.

\begin{tabular}{|c|c|c|}
\hline Code Name & Developer/Authors & \\
\hline $\begin{array}{l}\text { 1DB-2DB-3DB: 1-, 2-, 3- } \\
\text { Dimensional Diffusion- } \\
\text { Burnup Code System. }\end{array}$ & $\begin{array}{l}\text { Winston Little - winston.little@pnl.gov } \\
\text { Pacific Northwest National Laboratory }\end{array}$ & \\
\hline $\begin{array}{l}\text { 3DDT: Multigroup Diffusion } \\
\text { Code System for Use in Fast } \\
\text { Reactor Analysis. }\end{array}$ & $\begin{array}{l}\text { Los Alamos National Laboratory, Los Alamos, New } \\
\text { Mexico under sponsorship of DOE-EH through the Energy } \\
\text { Science \& Technology Software Center, Oak Ridge, } \\
\text { Tennessee. }\end{array}$ & \\
\hline $\begin{array}{l}\text { A3MCNP: Automatic } \\
\text { Adjoint Accelerated MCNP }\end{array}$ & $\begin{array}{l}\text { ORNL } \\
\text { PSU }\end{array}$ & \\
\hline $\begin{array}{l}\text { ALPHA -Automated Linkage } \\
\text { of PHOENIX/PARAGON } \\
\text { and ANC }\end{array}$ & $\begin{array}{l}\text { Ahmet O. Erdemli - erdemlao@westinghouse.com } \\
\text { Westinghouse Electric Company }\end{array}$ & \\
\hline \begin{tabular}{|l|} 
ANC - Advanced Nodal \\
Code for all nuclear core \\
design calculation
\end{tabular} & $\begin{array}{l}\text { Baocheng Zhang - zhangb@westinghouse.com } \\
\text { Westinghouse Electric Company }\end{array}$ & \\
\hline Apollo-2 & Areva & * \\
\hline Artemis & Areva & $*$ \\
\hline \begin{tabular}{|l|} 
BISON-C: One-Dimensional \\
Discrete Ordinate Transport \\
and Burnup Calculation \\
Code System.
\end{tabular} & $\begin{array}{l}\text { Faculty of Physics and Nuclear Techniques, University of } \\
\text { Mining and Metallurgy, Cracow, Poland. }\end{array}$ & \\
\hline $\begin{array}{l}\text { CAFCA: Code for Advanced } \\
\text { Fuel Cycles Assessment }\end{array}$ & MIT & \\
\hline \begin{tabular}{|l|l|} 
CARO \\
\end{tabular} & Areva & * \\
\hline Casmo-4 & $\begin{array}{l}\text { Studsvik Scandpower, Inc. } \\
\text { (http://www.studsvikscandpower.com) }\end{array}$ & \\
\hline $\begin{array}{l}\text { CITATION-LDI 2: Nuclear } \\
\text { Reactor Core Analysis Code } \\
\text { System. }\end{array}$ & $\begin{array}{l}\text { T. B. Fowler } \\
\text { D. R. Vondy } \\
\text { G. W. Cunningham } \\
\text { Oak Ridge National Laboratory }\end{array}$ & \\
\hline COPERNIC & AREVA & $*$ \\
\hline COSI & $\begin{array}{l}\text { Developed by the Nuclear Energy Direction at CEA and, } \\
\text { the French Atomic Energy Commission }\end{array}$ & \\
\hline CPM-3 & EPRI & \\
\hline $\begin{array}{l}\text { DANESS - dynamic analysis } \\
\text { of nuclear energy system } \\
\text { strategies }\end{array}$ & $\begin{array}{l}\text { ARGONNE NATIONAL LABORATORY } \\
\text { NUCLEAR ENGINEERING DIVISION }\end{array}$ & \\
\hline
\end{tabular}




\begin{tabular}{|c|c|c|}
\hline DIF3D 8.0/VARIANT8.0 & Argonne National Laboratory & \\
\hline Dragon & Ecole Polytechnique de Montreal. & \\
\hline $\begin{array}{l}\text { FCSNE - Fuel Cycle } \\
\text { Services Needs Estimator }\end{array}$ & Sandia National Lab & \\
\hline FLICA-IIIF & AREVA & $*$ \\
\hline FORMOSA Suite & & * \\
\hline $\begin{array}{l}\text { FRANCO: Finite Element } \\
\text { Fuel Rod Analysis Code } \\
\text { System. }\end{array}$ & Penn State University, University Park, Pennsylvania. & \\
\hline $\begin{array}{l}\text { FRAPCON3: Fuel Rod } \\
\text { Thermal-Mechanical } \\
\text { Behavior }\end{array}$ & $\begin{array}{l}\text { W.N. Rausch, R.E. Williford, and D.D. Lanning } \\
\text { Pacific Northwest Laboratory } \\
\text { G.A. Berna and M.P. Bohn } \\
\text { EG\&G Idaho, Inc. }\end{array}$ & \\
\hline $\begin{array}{l}\text { FRAPTRAN - Fuel Rod } \\
\text { Analysis Program Transient }\end{array}$ & $\begin{array}{l}\text { Pacific Northwest National Laboratory } \\
\text { Richland, WA } 99352\end{array}$ & \\
\hline $\begin{array}{l}\text { GAPCON-THERMAL3: } \\
\text { Code System to Calculate } \\
\text { Fuel Steady State and } \\
\text { Transient Behavior. }\end{array}$ & $\begin{array}{l}\text { D. D. Lanning, C. L. Mohr, F. E. Panisko, and K. B. } \\
\text { Stewart }\end{array}$ & \\
\hline $\begin{array}{l}\text { GRASS-SST: Code System } \\
\text { to Predict Fission-Gas } \\
\text { Release \& Fuel Swelling. }\end{array}$ & $\begin{array}{l}\text { S. Zawadzki } \\
\text { Argonne National Laboratory, IL }\end{array}$ & \\
\hline $\begin{array}{l}\text { GRENADE: Green's } \\
\text { Function Nodal Algorithm } \\
\text { for the Diffusion Equation. }\end{array}$ & $\begin{array}{l}\text { V.N. Anghel, T.A. Beu, D.I. Simionovici } \\
\text { Institute for Nuclear Power Reactors }\end{array}$ & \\
\hline KENO & ORNL & \\
\hline $\begin{array}{l}\text { LAPUR5.2: BWR Core } \\
\text { Stability Measurements. }\end{array}$ & Oak Ridge National Laboratory, Oak Ridge, Tennessee. & \\
\hline LYNXT & AREVA & * \\
\hline MARKAL & & * \\
\hline MCNP5/MCNPX & Los Alamos National Laboratory & \\
\hline $\begin{array}{l}\text { MCRAC: Multiple Cycle } \\
\text { Reactor Analysis Code. }\end{array}$ & $\begin{array}{l}\text { B.G. Petrovic, T. Smuc, D. Pevec, and D. Grgic } \\
\text { Ruder Boskovic Institute }\end{array}$ & \\
\hline MICROBURN-B2 & AREVA & * \\
\hline $\begin{array}{l}\text { MONK 6.3: A General } \\
\text { Purpose Monte Carlo } \\
\text { Neutronics Code System. }\end{array}$ & $\begin{array}{l}\text { R J Brissenden, RPD, AEE Winfrith, UKAEA } \\
\text { A.F. Albornoz } \\
\text { Centro Atomico Bariloche } \\
\text { CNEA, Argentina }\end{array}$ & \\
\hline $\begin{array}{l}\text { MONTEBURNS 2.0: } \\
\text { Automated, Multi-Step } \\
\text { Monte Carlo Burnup Code }\end{array}$ & $\begin{array}{l}\text { Los Alamos National Laboratory, } \\
\text { Los Alamos, New Mexico, U.S.A. }\end{array}$ & \\
\hline
\end{tabular}




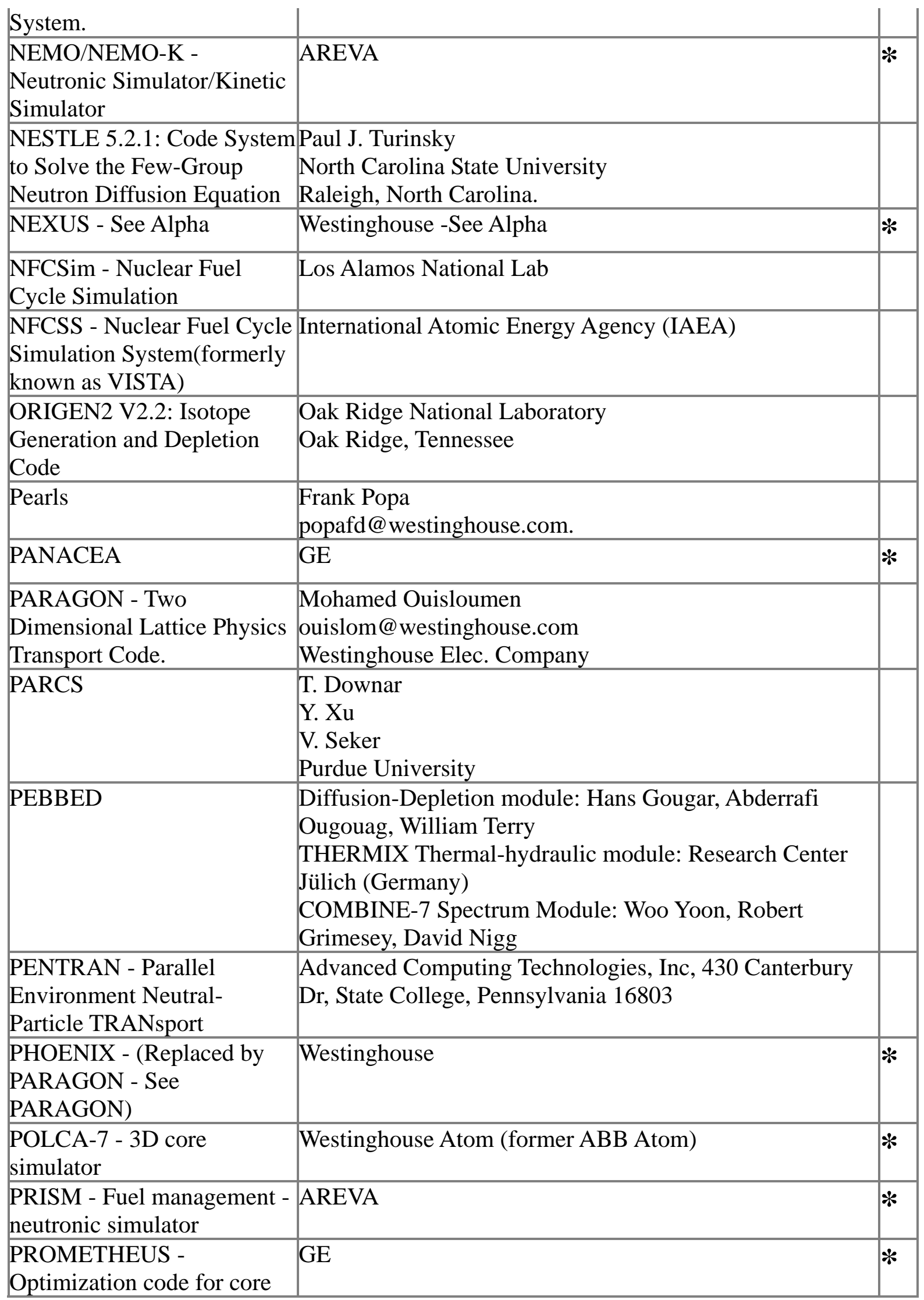


loadings and control blade positions for a given design.

PSU-LEOPARD/RBI 90.1: AB.G. Petrovic, T. Smuc, D. Pevec, and D. Grgic Spectrum Dependent Non- $\quad$ Ruder Boskovic Institute

Spatial Depletion Code.

RCT - A code to reconstruct Argonne National Laboratory

pin power and burnup

REBUS-3/VARIANT8.0: Argonne National Laboratory

Code System for Analysis of

Fast Reactor Fuel Cycles.

REBUS-PC 1.4: Code

System for Analysis of

Research Reactor Fuel

Cycles.

REFREP: A Near-Field

A. Hautojarvi and T. Vieno

Model For A Spent Fuel

Repository.

RODEX - Fuel management AREVA

- fuel rod

SCALE 6: Standardized

Computer Analyses for

Licensing Evaluation

Modular Code System.

SCANS 1A: Shipping Cask

Design Review Analysis.

SCIENCE - Fuel

management

SIMULATE-3

SMAFS: Steady-State

Analysis Model for

Advanced Fuel Cycle

Schemes.

SNAP - Symbolic Nuclear

Analysis Package

TACLE

TACO3 - Fuel management - AREVA

fuel rod

TRACE -The TRAC/RELAP Nuclear Regulatory Commission

Advanced Computational

Engine

TRIGLAV - Code System to Andrej Trkov

calculate mixed fuel reactor cores in TRIGA MARK II

research reactor.

"Jozef Stefan" Institute,

Reactor physics division

Jamova 39, PO. BOX 3000 


\begin{tabular}{|l|l|l|} 
& $\begin{array}{l}1001 \text { Ljubljana, Slovenia } \\
\text { E-mail: tomaz.zagar@ijs.si }\end{array}$ & $*$ \\
\hline TRITON - SCALE module & ORNL & \\
\hline $\begin{array}{l}\text { V:BUDS - visualize: burnu, } \\
\text { depletion, spectrum }\end{array}$ & $\begin{array}{l}\text { Erich A. Schneider* } \\
\text { Joshua G. Barratt } \\
\text { K. Bingham Cady } \\
\text { Mark R. Deinert } \\
\text { *Los Alamos National Laboratory } \\
\text { Cornell University }\end{array}$ & \\
\hline VEGAS & Los Alamos National Laboratory & \\
\hline $\begin{array}{l}\text { VENTURE-PC 2: A Reactor } \\
\text { Analysis Code System. }\end{array}$ & $\begin{array}{l}\text { A. Shapiro, H.C. Huria, and K.W. Cho } \\
\text { University of Cincinnati }\end{array}$ & \\
\hline VISION & $\begin{array}{l}\text { Argonne National Laboratory } \\
\text { Idaho National Laboratory }\end{array}$ & \\
\hline $\begin{array}{l}\text { VISTA - Replaced By } \\
\text { NFCSS - See NFCSS }\end{array}$ & IAEA & \\
\hline $\begin{array}{l}\text { VPI-NECM: Nuclear } \\
\text { Engineering Computer } \\
\text { Models for In-Core Fuel } \\
\text { Management Analysis. }\end{array}$ & $\begin{array}{l}\text { Ing. Jiri HONOMICHL } \\
\text { Power Machinery Plant }\end{array}$ & \\
\hline $\begin{array}{l}\text { VSOP94: Very Superior Old } \\
\text { Programs - Computer Code } \\
\text { System for Reactor Physics } \\
\text { and Fuel Cycle Simulation. }\end{array}$ & $\begin{array}{l}\text { E. Teuchert, K.A. Haas } \\
\text { Forschungszentrum Juelich GmbH. (KFA) }\end{array}$ & \\
\hline
\end{tabular}




\section{Attachment 4 - Examples of Queries}

Any user with SQL knowledge will be able to use this data base. Those who do not know the structured query language should look at the following resource:

http://www.1keydata.com/sql/sql-syntax.html

Example 1: List codes by NFC classification

PHP Code:

$<$ ?php

include('config.php');

\$typecount $=\operatorname{array}(\Theta, \Theta, \Theta, \Theta, \Theta, \Theta, \Theta, \Theta, \Theta)$;

\$result = mysql_query $($ "SELECT * FROM `codeProbType`") or trigger_error(mysql_error());

while $($ \$row $=$ mysql_fetch_array $(\$ r e s u l t))\{$

foreach (\$row AS \$key => \$value) \{ \$row[\$key] = stripslashes (\$value); \}

extract (\$row);

if (\$typeID == 2) $\{$ \$typecount $[0]++;\}$

elseif (\$typeID == 4) $\{$ \$typecount [1]++; \}

elseif (\$typeID ==6) \{ \$typecount [2]++; \}

elseif (\$typeID == 8) \{ \$typecount[3]++; \}

elseif (\$typeID == 1) $\{$ \$typecount [4]++; \}

elseif (\$typeID == 3) \{ \$typecount [5]++; \}

elseif (\$typeID == 5) $\{$ \$typecount [6]++;

elseif (\$typeID ==7) \{ \$typecount [7]++;

elseif (\$typeID ==9) $\{$ \$typecount [8]++;

elseif (\$typeID $==10$ ) $\{$ \$typecount [9]++; \}

\}

echo "<table border='1' width='400' $><$ tr $><$ td

width $=200<<$ b $>$ Problem Type: $</$ b $></$ td $>$ ";

echo "<td width=200 $><$ b $>$ Number of Codes: $</ b></$ td $></$ tr $>$ ";

$\$ \mathrm{i}=0$;

\$temptype = mysql_query ("SELECT * FROM `probType` ORDER BY 'sortorder'"); 


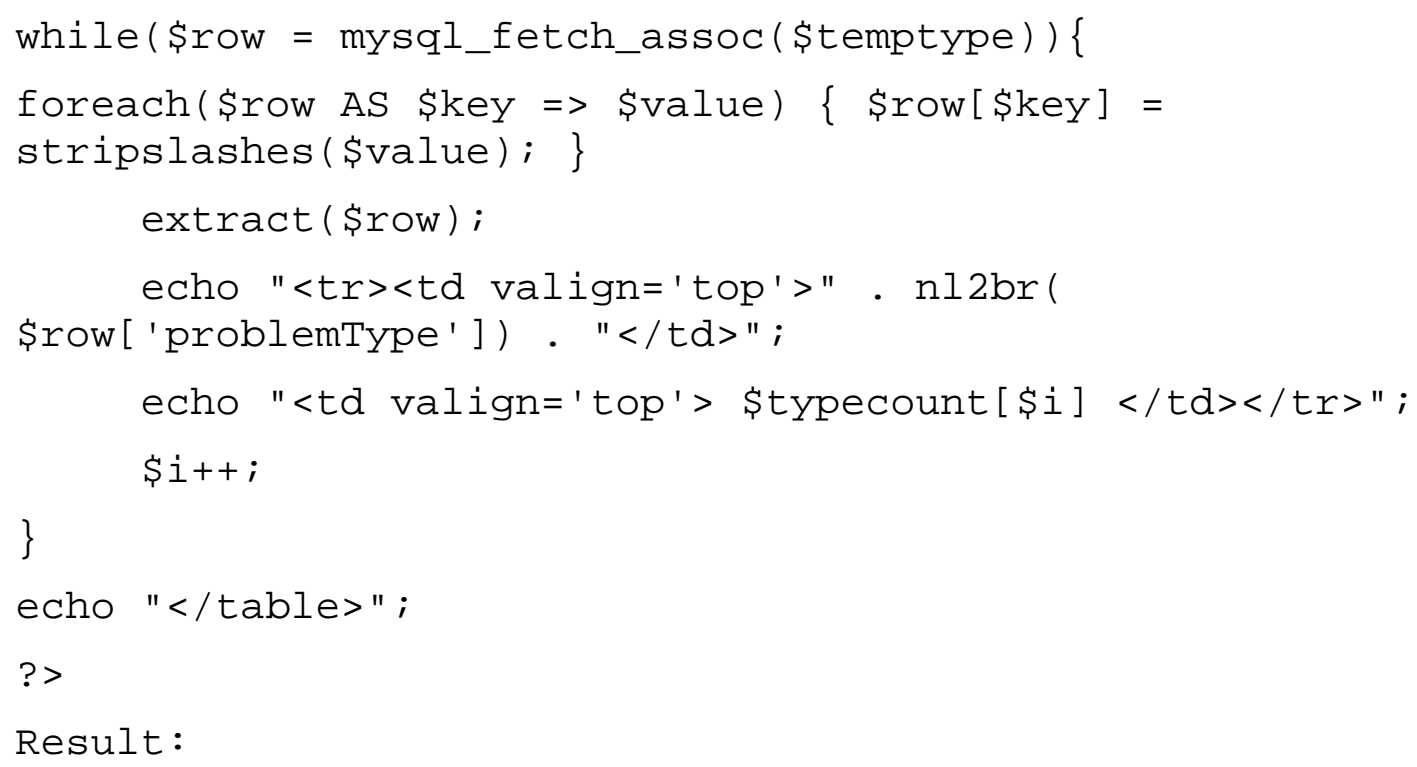

Result:

\begin{tabular}{|l|c|}
\hline Problem Type: & Number of Codes: \\
\hline Mining/Milling & 0 \\
\hline Conversion & 0 \\
\hline Enrichment & 1 \\
\hline Fuel Fabrication & 0 \\
\hline Reactor Analysis & 56 \\
\hline Spent Fuel Storage & 4 \\
\hline Fuel Reprocessing & 0 \\
\hline Waste Disposal & 0 \\
\hline Top level/Complete Fuel Cycle & 10 \\
\hline Other/Unknown & 8 \\
\hline
\end{tabular}

Another search to list all the codes of a specific problem type would be the following:

SELECT name FROM 'code` WHERE ‘codeID` IN (SELECT 'codeID ' FROM 'codeProbType`WHERE 'typeID`= '1') ORDER BY 'codeID`;

Where typeID corresponds to a specific problem type designed into the database.

Example 2: List I/O of a particular code

This is for the 1DB-2DB-3DB code that has a codeID of 1 .

PHP Code:

$<$ ?php

include( 'config.php'); 


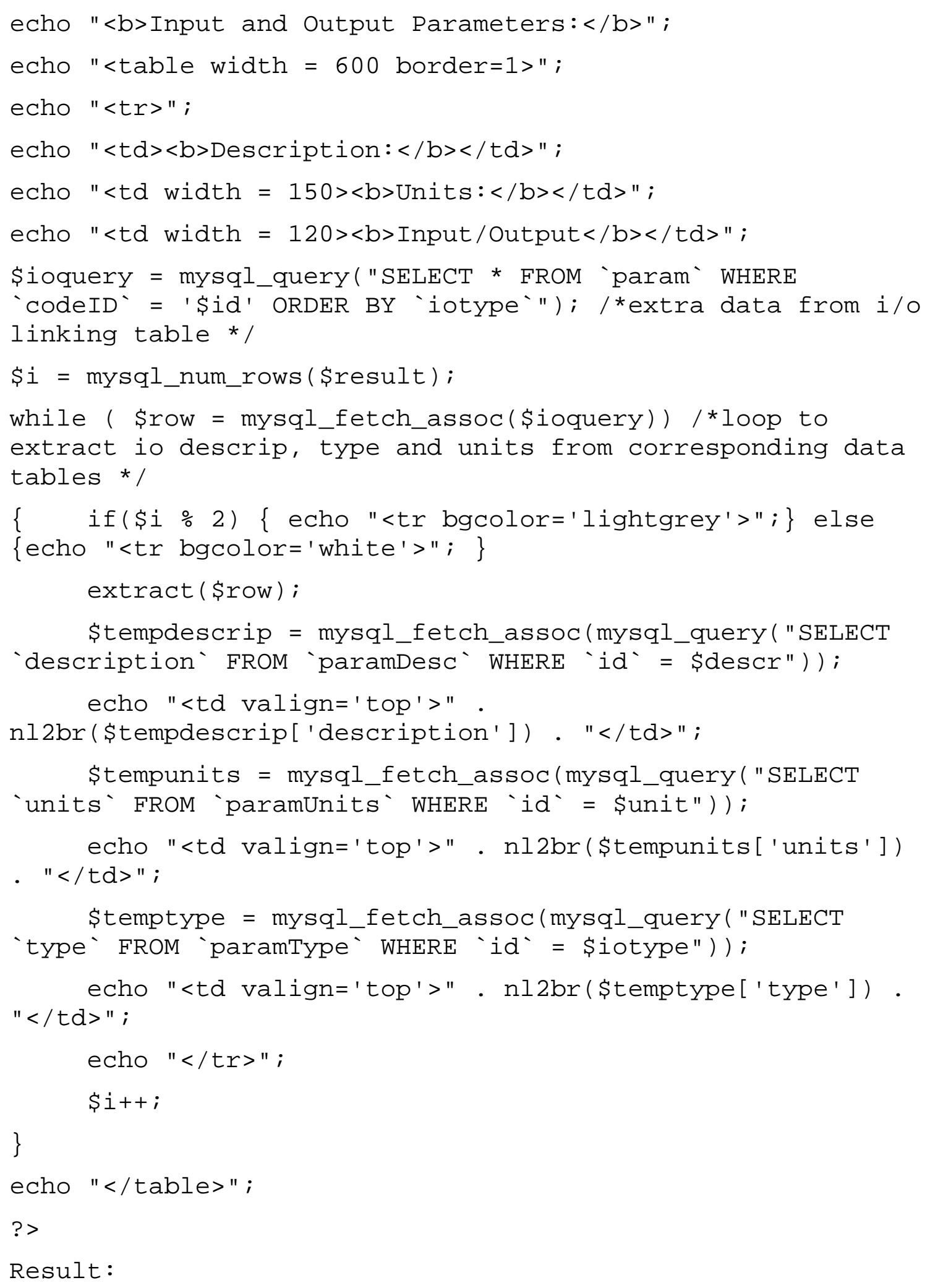

\begin{tabular}{|l|l|l|}
\hline Description: & Units: & Input/Output \\
\hline Fission energy & MEV/FISSION & Input \\
\hline
\end{tabular}




\begin{tabular}{|l|l|l|}
\hline Max number of outer iterations & Integer/Float & Input \\
\hline Max inner iterations per group & Integer/Float & Input \\
\hline Inversion direction & Integer/Float & Input \\
\hline Flux input & Integer/Float & Input \\
\hline Flux dump & Integer/Float & Input \\
\hline Profile dump (Power \& Flux) & Integer/Float & Input \\
\hline Time limit & Integer/Float & Input \\
\hline Buckling & cm^-2 & Input \\
\hline Eigenvalue convergence criterion & Integer/Float & Input \\
\hline Flux convergence criterion & Integer/Float & Input \\
\hline Over-Relaxation factor & Integer/Float & Input \\
\hline Power (MWt)/Neutron source rate & MWt/N Source Rate & Input \\
\hline External source distribution & \#/CC-SEC & Input \\
\hline External source spectrum & Integer/Float & Input \\
\hline Print/Output Verbosity & Integer/Float & Input \\
\hline Number of burnup steps & Integer/Float & Input \\
\hline Geometry type/description & Integer/Float & Input \\
\hline Calculation Type & Integer/Float & Input \\
\hline Eigenvalue Type & Integer/Float & Input \\
\hline Number of neutron energy groups & Integer/Float & Input \\
\hline Number of Upscattering Terms & Integer/Float & Input \\
\hline Number of Downscattering Terms & Integer/Float & Input \\
\hline Number of added lots before N,2N & Integer/Float & Input \\
\hline Include N2N in keff & Integer/Float & Input \\
\hline Number of Mesh Intervals(X,Y,Z) & Integer/Float & Input \\
\hline Number of burnup isotopes & Integer/Float & Input \\
\hline Number of activities & Integer/Float & Input \\
\hline Boundary Conditions & Integer/Float & Input \\
\hline Number of zone specifications & Integer/Float & Input \\
\hline Number of material zones & & Input \\
\hline Number of input materials & Input \\
\hline Avg activity & Output \\
\hline
\end{tabular}




\begin{tabular}{|l|l|l|} 
Flux spectrum at point & \#/CC-SEC & Output \\
\hline Power Density & MW/liter & Output \\
\hline Zone mass & $\mathrm{kg}$ & Output \\
\hline Zone volume & liters & Output \\
\hline Material Inventory & $\mathrm{kg}$ & Output \\
\hline Leakage (left, right, top, bottom, back, front) & Integer/Float & Output \\
\hline abs(1-Lambda) & Integer/Float & Output \\
\hline Eigenvalue (per iteration) & Integer/Float & Output \\
\hline Total activity & \#/sec & Output \\
\hline
\end{tabular}

Example 3: Search for codes that perform fast spectrum or thorium cycle calculations. mysql> SELECT name FROM code WHERE features like "thorium"; Empty set $(0.00 \mathrm{sec})$

mysql> SELECT name FROM code WHERE features like "fast";

Empty set $(0.00 \mathrm{sec})$

mysql> SELECT id FROM paramdesc WHERE description like "thorium";

Empty set $(0.00 \mathrm{sec})$

mysql> SELECT id FROM paramdesc WHERE description like "fast";

Empty set $(0.00 \mathrm{sec})$ 